\title{
An improved empirical model of electron and ion fluxes at geosynchronous orbit based on upstream solar wind conditions.
}

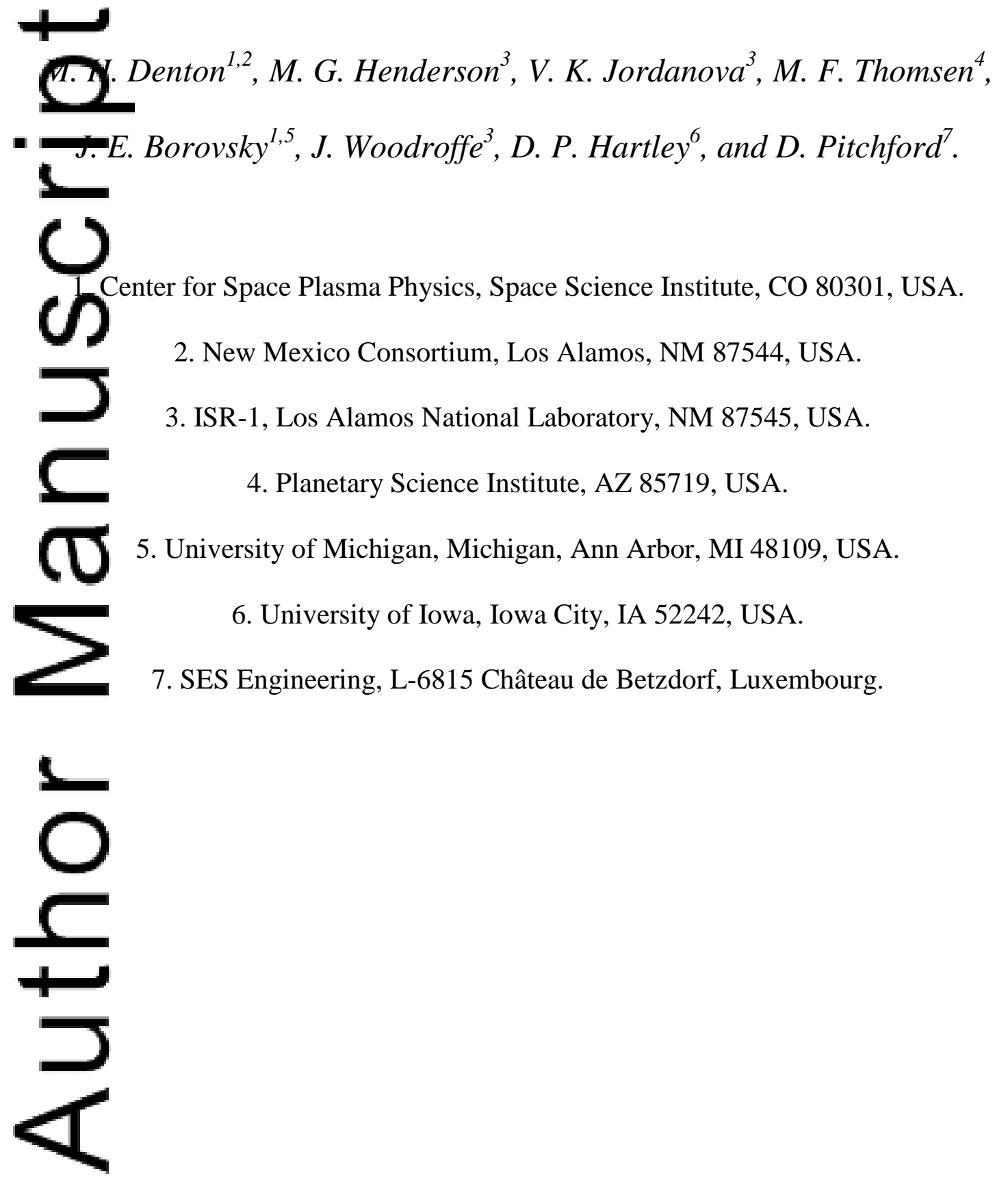

This is the author manuscript accepted for publication and has undergone full peer review but has not been through the copyediting, typesetting, pagination and proofreading process, which may lead to differences between this version and the Version of Record. Please cite this article as doi: 10.1002/2016SW001409

This article is protected by copyright. All rights reserved. 


\begin{abstract}
A new empirical model of the electron fluxes and ion fluxes at geosynchronous orbit (GEO) is introduced, based on observations by Los Alamos National Laboratory (LANL) satellites. The model provides flux predictions in the energy range $\sim 1 \mathrm{eV}$ to $\sim 40 \mathrm{keV}$, as a function of local-time, energy, and the strengur of the solar-wind electric field (the negative product of the solar wind speed and the $\mathrm{z}$ componer of the magnetic field). Given appropriate upstream solar-wind measurements, the model provides fore ast of the fluxes at GEO with a $\sim 1$ hour lead time. Model predictions are tested against in-sample 8 sgations from LANL satellites, and also against out-of-sample observations from the CEASE-Ifugetor on the AMC-12 satellite. The model does not reproduce all structure seen in the observations. However, for the intervals studied here (quiet and storm times) the Normalized-RootMean-Squarea-Deviation (NRMSD) $<\sim 0.3$. It is intended that the model will improve forecasting of the spaced nvironment at GEO and also provide improved boundary/input conditions for physical models of the magnetosphere.
\end{abstract}

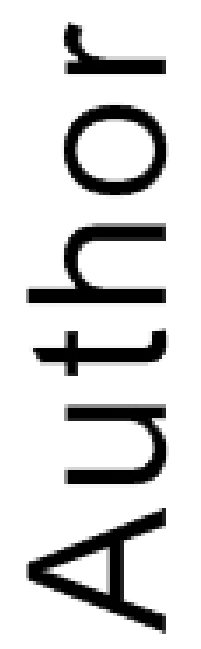




\section{Introduction}

Geosynchronous orbit (GEO), at a radial distance of $6.6 \mathrm{R}_{\mathrm{E}}$ (Earth radii), is one of the most popular locations for communications, scientific, and military satellites (see Figure 1). This is primarily due to the fact that satellites located in this orbit have an orbital period of 24 hours, allowing them to remain at the same geographic longitude above the Earth during their operational lifetime. Predictions of the -

plasma endironment encountered by satellites at GEO [Purvis et al., 1984; O'Brien and Lemon, 2007; Thomsen t al. 2007; Sicard-Piet et al., 2008; O'Brien, 2009; Ginet et al., 2014; Hartley et al., 2014; Ganushkifetal., 2013; 2014; 2015; Denton et al., 2015] provide spacecraft designers and operators with estinratrof the plasma conditions (e.g. the ion flux and the electron flux) that satellite hardware will be subjected to on orbit. If such predictions are based on upstream solar-wind conditions (e.g. measured oy the ACE satellite or the DSCOVR satellite situated in Lissajous orbits at the L1 Lagrangia phe between the Earth and the Sun) then this allows a lead time of around one hour from the flux predictions being made to when such fluxes may be encountered. Since elevated fluxes are generally considered a hazard for satellites, a lead time of around one hour can be used to potentially take remelial action with the intention of mitigating damaging effects upon the satellite hardware. Understanding the environment at GEO is one scientific topic where the operational community and the scientifommunity both invest significant effort and where each communities priorities may be aligned [Q'Brien et al., 2013].

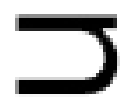

In addition the hardware-related uses of electron and ion flux predictions, a variety of scientific 
models of the inner magnetosphere also use fluxes at GEO as their outer boundary conditions (e.g. Jordanova et al. [1998; 2003], Zaharia et al. [2005; 2006], Katus et al. [2014]). Hence, development of improved predictions of the fluxes at GEO has the potential to benefit both the scientific and operationalcommunities.

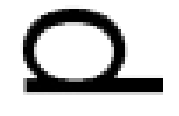

In a recent study we introduced a new model of the ion and electron fluxes at GEO in the energy range $\sim 1 \mathrm{eV}$ to $40 \mathrm{geV}$ as a function of local time, geomagnetic activity, and solar-activity [Denton et al., 2015]. The National Laboratory (LANL) satellites based at GEO. Magnetospheric Plasma Analyzer (MPA) instruments (electro-static analyzers) onboard the satellites measure both the electron and the ion energy-pe distributions between $\sim 1 \mathrm{eV} / \mathrm{q}$ and $\sim 40 \mathrm{eV} / \mathrm{q}$ [Bame et al., 1989; Thomsen et al., 1999]. In bilef each point in the entire MPA dataset (over 80 satellite-years of data) was allocated to the appropiate bin based on an array of 40 energies (equally spaced logarithmically between $1 \mathrm{eV}$ and $40 \mathrm{eV}$ ), 28 discrete values of the Kp index [Bartels et al., 1939; Thomsen, 2004], for both ipns and electrons. Solar activity variations were included in the model by carrying out the above binfing for four ranges of the F10.7 index (all F10.7, F10.7 < 100, $100<\mathrm{F} 10.7<170$, and F10.7 > 170). Statistical averaging for each grid allowed the mean, median, and standard deviation for each bin to be calculated whilst bi-linear interpolation allowed flux predictions to be made for any chosen input valume model also returned predictions of the 5th, 25th, 75th, and 95th percentiles of the flux values for any chosen combination of input values. Hence, in the published version of the original 
model, the user can input a particular energy, local time, and value of the Kp index, and the model will return a prediction of the electron flux and the ion flux to be encountered at GEO for the chosen energy, chosen local time, and chosen Kp index, at four different levels of solar activity [Denton et al., 2015].

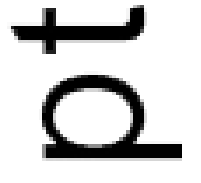

The bulk norphology of the electrons and ions at GEO, in the energy range sampled by LANL/MPA, has previqasly peen shown to be well-correlated with the level of magnetospheric convection [Korth et al., 1999; Dron et al., 2005; 2007; Lavraud et al., 2005]. And since the Kp index, with a 3 hour cadence, is avery good proxy for this magnetospheric convection [Thomsen, 2004], then the original model predicted fluxes that were in reasonably good agreement with observations. However, two disadvantarise from use of the Kp index, with particular regard to predictions. Firstly, the $\mathrm{K}$ index (fr. Onhich $\mathrm{Kp}$ is derived) is an Earth-based index, constructed from magnetometer measurements of the horizontal component of the terrestrial magnetic field. Hence, estimates of flux at Earth (gevoymronous orbit), based on the Kp index, are only available on an instantaneous basis (i.e. a 'nowcas' $($ ), rather than being true advance predictions (i.e. a 'forecast'). Secondly, the fluxes at GEO are regula yopserved to fluctuate much more rapidly than three-hour time cadence of the Kp index, typically in response to dynamic changes in the solar wind with timescales much less than one hour in duration. Thus, our desire for a new and improved predictive model is driven by the following criteria: (i) that thedel should be driven by some set of parameters that are regularly measured in the solar wind, upstream of the Earth, and thus provide at least a one-hour time interval between prediction 
of the fluxes and arrival of the fluxes at GEO, (ii) that the activity parameters should be capable of a time cadence of at least one hour, and preferably as short as one minute, and (iii) that the new model produce flux predictions that are, in the majority of cases, comparable with, or better than, the previous version or the model. As outlined below, the results summarized in this study indicate that we have largely achiev our intended aims by parameterizing the new model with the measured value of the solar-wing electric field at the L1 point. The developmental methodology used in formulating the new model is outhned in detail in Section 2, comparisons between model predictions and in-situ observations fluxes are made, along with goodness-of-fit calculations, in Section 3, and a discussion of the strenoths, and weaknesses of the current model, and a summary, are provided in Section 4.

\section{Mode Fethodology}

The methddogy followed in generating a new model of the fluxes at GEO is very similar to that used in the previoys model, and described in detail in Denton et al. [2015]. The dataset for the model comprises $\sim 82$ satellite-years of electron and ion observations made between 1989 and 2007 by the LANL/MRA instruments flown on seven satellites at GEO. All flux measurements during this period are utilize wh concurrent solar-wind measurements are available in the OMNI2 database [King and Papitashv extremely high solar-wind pressure events) are excluded from the binning. One difference between this study and the previous Denton et al. [2015] study is that here we do not remove periods of exceptionallyigh spacecraft surface charging. The methodology to correct the particle energies 
resulting from the charging (due to acceleration towards the spacecraft, or repulsion away from the spacecraft), is considered robust [Thomsen et al., 1999].

In brief, alı available flux values (for electrons and ions) are binned into one-hour width bins in local time, 40 armically spaced bins in energy (from $1 \mathrm{eV}$ to $40 \mathrm{keV}$ ), and 32 equal-width bins in $\mathrm{v}_{\mathrm{sw}} \mathrm{B}_{\mathrm{z}}$ (from -8000 to $+8000 \mu \mathrm{V} \mathrm{m} \mathrm{m}^{-1}$ ). This binning yields a set of three-dimensional data-cubes that contain the man, standard-deviation, and the $5^{\text {th }}, 25^{\text {th }}, 50^{\text {th }}, 75^{\text {th }}$, and $95^{\text {th }}$ percentiles of all data contributigen bin (see Figure 3). In order to provide the average conditions at any local-time, energy or interpolation (with respect to $-\mathrm{v}_{\mathrm{sw}} \mathrm{B}_{\mathrm{z}}$ ) is used. The local time (in hours), the energy (in eV), and the negative prouret of the solar wind flow speed $\left(\mathrm{v}_{\mathrm{sw}}\right.$ in units of $\left.\mathrm{km} \mathrm{s}^{-1}\right)$ and the $\mathrm{z}$-component of the solarwind magfelic field ( $\mathrm{B}_{\mathrm{z}}$ in GSM coordinates in units of $\left.\mathrm{nT}\right)$, are chosen by the user. This product is the solar-wing electric field $\left(-\mathrm{v}_{\mathrm{sw}} \times \mathrm{B}_{\mathrm{z}}\right)$ in units of $\mu \mathrm{V} \mathrm{m} \mathrm{m}^{-1}$ and in this parameterization, a solar wind speed of $450 \mathrm{~km} \mathrm{~s}^{-1}$ in a magnetic field value of $\mathrm{B}_{\mathrm{z}}=-14.7 \mathrm{nT}(\mathrm{GSM})$ yields an electric field of +6615 $\mu \mathrm{V} \mathrm{m}{ }^{-1}$. is generally accepted that, as with the Kp index, the solar-wind electric field is reasonably well-correated with activity in the magnetosphere, although the detailed micro-physics that control the coupling theyond the scope of this paper (see Newell et al. [2007]; Borovsky [2013; 2014]; McPherron et gl. [2015] for further discussions on this topic).

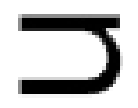

Although it planned to evaluate more advanced coupling functions in future, use of the $-v_{\mathrm{sw}} \mathrm{B}_{\mathrm{z}}$ 
parameter has the advantage of being well-known in the science and operational community, easily computed, and widely available over the duration of the LANL/MPA dataset. In addition, this parameter will be available in future via the continued operation of the ACE and DSCOVR satellites. Solar wint aata, propagated to the magnetopause, are taken from the high-resolution OMNI2 database [King andrashvili, 2005] and MPA flux values are only included in the binning if solar-wind data are available at the time of each data-point. To ensure a sufficient amount of data in each bin we have limited th binging to $-\mathrm{v}_{\mathrm{sw}} \mathrm{B}_{\mathrm{z}}$ values between -8000 and $+8000 \mu \mathrm{V} \mathrm{m}^{-1}$, and do not provide separate prediction different values of the F10.7 index. [Note: The maximum flux variation between solar maximumandsolar minimum in the previous model was around a factor of 2 , and only that large for a small range of energies $(\sim \mathrm{few} \mathrm{keV})$. It is envisaged that users who will have a particular interest in solar cyclects will be able to examine the F10.7 variations in the previous model to gain insight into the extred small changes with F10.7 in the new model].

The mean, stantdard-deviation, and the $5^{\text {th }}, 25^{\text {th }}, 50^{\text {th }}, 75^{\text {th }}$, and $95^{\text {th }}$ percentiles in each bin are calculated for ions and electrons. Figure 2 contains a schematic representation of the binning process and Figure 3 shows tergults of this binning for the mean electron flux, and the mean ion flux, at two example energies. Theplots in this figure demonstrate how differences in the orientation of the interplanetary magnetic field direction (IMF), either northwards or southwards, radically change the average measured at GEO for both the electrons and the ions. Clearly, such differences are neglected when only considering the overall level of convection (proxied by $\mathrm{Kp}$ ) as is the case in our previous 
model [Denton et al., 2015]. Thus, we expect an increase in the prediction accuracy of the new model as a result. Figure 4 contains example surface plots showing the electron and ion flux variability, as a function of energy and local-time, for the one particular case when $-v_{s w} B_{z}=-2000 \mu V m^{-1}$.

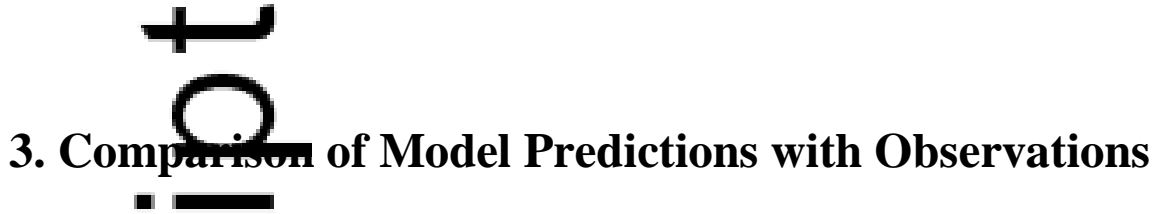

In compaling observations with model predictions the aim is to evaluate both the general level of prediction(abili)y of the model (goodness-of-fit), and also the incident solar-wind conditions for which the mode $\mathrm{p}$ ections may be more, or less, accurate. Here, model predictions are compared against two differem those from theindependent CEASE-II instrument [Dichter et al., 1998] onboard the AMC-12 satellite, also located at GEO. The root-mean-squared deviation (RMSD) and the normalized root-meansquared deriton (NRMSD) between the measured fluxes and the model predictions are calculated via the equation

$$
\operatorname{NRMSD}=\operatorname{RMSD} /(\overline{\mathrm{x}})=\sqrt{\frac{\sum_{\mathrm{x}=1}^{\mathrm{n}}\left[\left(\mathrm{x}_{\mathrm{i}, \text { model }}-\mathrm{x}_{\mathrm{i}, \text { measured }}\right)^{2}\right]}{\mathrm{n}}} /(\overline{\mathrm{x}})
$$

where $n$ is the number of data points over the range of the comparison and $\bar{x}$ is the mean value of $x$ over this ange. Both NRMSD and RMSD are calculated in order to provide metrics with which to quantify wrodel accuracy (cf. Legates and McCabe Jr., 1999; Ganushkina et al., 2015) although a wide spectrum of other metrics may be used when comparing models to data [Koh et al., 2012], each with panet ar strengths and weaknesses. There are no universally accepted metrics for what 
represents a 'good' NRMSD value, and certainly the calculated NRMSD values depend heavily on the interval being studied. However, small values represent a better match between observations and predictions than large values. The special case of $\mathrm{RMSD}=0(\mathrm{NRMSD}=0)$ would represent a perfect forecast orthe variation in the time-series being evaluated.

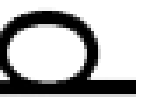

\subsection{Comparison with LANL/MPA observations}

A compan model predictions with the LANL/MPA observations at GEO is made for a calm five-day prif during 2004. Figure 5 contains electron observations and ion observations (at energies $\sim 32 \mathrm{keV}$ ) from the LANL-02A satellite (solid black line) along with model predictions from the Kp version of the model (left column) and the new model driven by the solar wind electric field, $-\mathrm{v}_{\mathrm{sw}} \mathrm{B}_{\mathrm{z}}$ (right col Although the original aim was to provide a model with a much higher temporal resolution than the Kp model, on implementation it was found that rapid fluctuations in the $-\mathrm{v}_{\mathrm{sw}} \mathrm{B}_{\mathrm{z}}$ parameteresulted in rapid oscillations in model predictions. These do not accurately represent the actual Gorrvations at GEO. Although it is unclear on what timescale the bulk magnetosphere responds o changing solar-wind electric fields (likely a complicated function of particle energy, species, ti re-1y story of the system, etc.), here the model results are smoothed with a five-minute boxcar average_this can be changed as required by the user) so as to smooth the oscillations in one-minute high-resolution OMNI model input data. Note: the Kp model is naturally smoothed due to the 3-hour cadence of Kp index. The solid red line in Figure 5 is the predicted mean flux from the model, and the solid purple line is the median. The 5th, $25 \mathrm{th}, 75 \mathrm{th}$ and 95 th percentiles are indicated by the dashed 
and dotted purple lines (the standard deviation is not shown). The Kp index and the $-\mathrm{v}_{\mathrm{sw}} \mathrm{B}_{\mathrm{z}}$ parameter are plotted in the bottom row. The RMSD and NRMSD values for the model-data comparisons are also provided in the top right of each plot. Both versions of the model provide a reasonably good fit to the data with NRSD values between $\sim 0.14-0.25$. Little difference is apparent between the models during thendim conditions, with the observed flux almost always falling within the 5th-to-95th percentilerange of the model predictions.

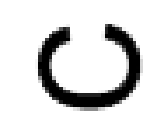

The plots ghen in Figure 6 follow the same format but this time for ions and electrons with energies $\sim 10 \mathrm{keV}$ ) during a highly dynamic and disturbed period, also in 2004 . The model predictions closely follow the trend of the observations and for this period, even during some of the most dynamic changes in the Kp and in $-\mathrm{v}_{\mathrm{sw}} \mathrm{B}_{\mathrm{z}}$. The NRMSD values are between $\sim 0.15-0.21$ for the new $-\mathrm{v}_{\mathrm{sw}} \mathrm{B}_{\mathrm{z}}$ model and the ofingl Kp model at these times, and these values are typical of a range of other energies between $-40000 \mathrm{eV}$. Of course the $-\mathrm{v}_{\mathrm{sw}} \mathrm{B}_{\mathrm{z}}$ model also has the distinct advantage that it can make flux-preminom $\sim 1$ hour prior to the event, provided the upstream solar-wind electric field value is known. Again, the observed fluxes fall within the 5th-to-95th percentile range predicted by both models dy itIg almost the entire period under study, although the sharp drop in the ion flux at the start of day 94 is not predicted by either model.

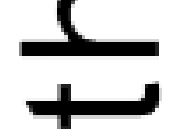

A complemparison of flux-predictions from the two different models at all observed energies can be made examining energy-time spectrograms of flux values from in-situ observations, along with 
simulated spectra from model predictions. Figure 7 contains electron (left column) and ion (right column) flux spectrograms from the LANL-02A satellite (top row) with simulated spectra from the Kp model (middle row) and the new $-\mathrm{v}_{\mathrm{sw}} \mathrm{B}_{\mathrm{z}}$ model (bottom row). The model spectra show the mean-flux predictions irom each model (although it is straight-forward to also evaluate the 5th, 25th 50th, 75th or 95th percentil flux-predictions, along with the standard deviation). The orange dashed line indicates local noorand the black dashed line indicates local midnight. Note: the observations of electron fluxes below $\sim 10$ should be treated with caution due to the possible presence of photoelectrons and secondary

Both the $-\mathrm{V}_{\mathrm{sw}} \mathrm{B}_{\mathrm{z}}$ and the Kp model flux spectra show many similarities to the observed LANL-02A spectra whedel flux values being broadly comparable to the observations. However, it is clear that there ard gnificant differences at most energies. With respect to the electrons, the high fluxes observeatenergies up to $10 \mathrm{keV}$ by LANL-02A after 15 UT are not fully captured by either model. The Kprmereproduces elevated fluxes at this time but their spatial structure is clearly affected by the three-hour cadence of the Kp index. The $-\mathrm{v}_{\mathrm{sw}} \mathrm{B}_{\mathrm{z}}$ model reproduces rapid fluctuations in the fluxes that result 1 changes in the solar-wind electric field, but in general these are not seen in the observations_nrior to $15 \mathrm{UT}$. With respect to the ions, both the Kp and the $-\mathrm{v}_{\mathrm{sw}} \mathrm{B}_{\mathrm{z}}$ model reproduce the appearance of a low-energy population (the ion plasmasphere) observed by LANL-02A but the model fluxes arewhat lower than actually observed. 


\subsection{Comparison with independent AMC-12/CEASE-II observations}

As in evaluation of the previous model, in order to provide independent testing of the model veracity (at least for the electron observations) we carry out a comparison of model predictions with electron flux observations from the CEASE-II sensor onboard the AMC-12 satellite at GEO. This comparison Kp reach d a maximum $\sim 6$ and the Dst index reached a maximum excursion $\sim-100$ at the start of the day. As as peviously noted [Denton et al., 2015] there is a semi-constant offset between CEASE-II fluxes and model predictions and hence to account for this difference we multiply the CEASE-II fluxes by afactor of $\sim 15$ at all times. Since no cross-calibration between the MPA and CEASE-II instruments took place prior to launch, this adjustment is akin to on-orbit cross-calibration of the fluxes. for future comparison of model fluxes with measured fluxes from different satellites it would be es ary to evaluate the need for use of an appropriate cross-calibration factor.

Figure electron fluxes measured by the CEASE-II instrument during a 24-hour period in

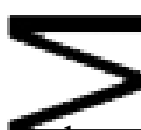
color-spegtrogram format, as a function of energy and time (top plot), along with the model electron flux predifon from the Kp model (middle panel) and the new $-\mathrm{v}_{\mathrm{sw}} \mathrm{B}_{\mathrm{z}}$ model (bottom panel). The Kp index and $-\mathrm{V}_{\mathrm{m}} \mathrm{B}_{\mathrm{z}}$ are also shown, demonstrating the activity levels during this day The predictions from each model demonstrate that the broad features observed at GEO by out-of-sample instruments such as GAcF-II, can be predicted, even during highly disturbed periods. The advantage of the $\mathrm{v}_{\mathrm{sw}} \mathrm{B}_{\mathrm{z}}$ model is,that the fluxes to be encountered by the AMC-12 satellite can be predicted $\sim 1$ hour in 
advance, given upstream solar wind measurements of the speed and z-component of the magnetic field.

\subsection{Spacecraft surface charging on LANL/MPA}

Along wint the electron and ion fluxes, the MPA instruments also measure the electrostatic surface on their individual design and construction details, spacecraft can charge positive or negative [DeFores 1972; Garrett, 1981; Farthing et al., 1982; Lanzerotti et al. 1998; Thomsen et al. 2013]. In the case ofthLANL satellites, the greatest level of charging occurs during hours of eclipse when the surface potential can reach 1000s Volts (negative) with respect to the ambient plasma. Such elevated charging can be detected by the observation of an ion-line in the ion flux measurements. This occurs due to porticles that are accelerated towards the spacecraft by the negative charge on the spacecraf $A$ example of such an ion-line can be seen between $\sim 18-22$ UT in the ion flux observatuons in Figure 7.

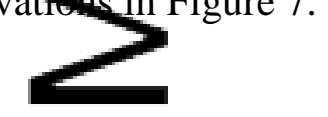

Since the MPA instruments regularly measure the spacecraft charging, it is straight-forward to extend the curren model to include predictions of spacecraft charging, via similar methodology as that used for the fluxes. Although each spacecraft charges differently depending on its construction, the environmental conditions that give rise to dangerous levels of surface charging on one satellite are likely to danger to other satellites passing through the region. Figure 9 shows the mean measured (negative) surface potential from all seven LANL satellites, in the same format as that used 
to calculate the flux distributions (as a function of $-\mathrm{v}_{\mathrm{sw}} \mathrm{B}_{\mathrm{z}}$ ) shown in Figure 3. It is clear from Figure 9 that the most severe surface charging of the LANL satellites occurs during southwards IMF- $\mathrm{B}_{\mathrm{z}}$ and at spatial locations around local midnight. Charging is greatly reduced during periods of positive IMF$\mathrm{B}_{\mathrm{z}}$. (cf. phots of spacecraft charging from LANL/MPA as a function of Kp, Dst, and $\mathrm{v}_{\mathrm{sw}}$ given in Denton ar by carrying out a bi-linear interpolation between the mean surface charging levels in the appropriate bins in Fire 9 , based on the prevailing solar-wind conditions and the satellite local time. In this respect the predictions of surface charging are calculated similarly to the model fluxes. It is planned that this predictive capability of model will be further developed in future versions.

\section{Discusion and Summary}

The ultimatal of much "space weather" research is to accurately predict the conditions to be encountereaby orbital hardware systems as far in advance as possible. Of course, it is nigh-on impossible for $100 \%$ accurate predictions to ever be achieved. However, by carrying out the work outlined bove, we aimed to achieve quantitative predictions that allow hardware operators and scientific nodglers the ability to predict fluxes in advance given knowledge of upstream solar wind parameter The absolute flux values (Figures 5 and 6), and the flux spectra (Figures 7 and 8), show that the $-\mathrm{V}_{\mathrm{sw}} \mathrm{B}_{\boldsymbol{1}}$ model provides reasonably accurate flux predictions at GEO $\sim 1$ hour in advance, providing Kno ledge of the solar wind electric field (e.g. from the ACE or DSCOVR satellites) is available. Sult knowledge is available in real-time (e.g. from the Space Weather Prediction Center 
(http://www.swpc.noaa.gov/).

With a view to potential changes that could improve future flux forecasts, it is important to be guided by knowitage of the physics of the inner magnetosphere. The current model, and the previous version, considere the time-history of the magnetosphere at the time of the predictions, or the explicit transport for plasma to migrate from the solar wind to the various locations around GEO. Drift times are enery dependent, and also dependent on the local convection strength. Such potentially non-linear ffects can be estimated but are not known without complex particle tracing calculations. Denton and Borovsky [2009] estimated transport timescales from the solar wind to various locations around GEO with timescales being of the order of $0 \mathrm{~h}$ to $17.5 \mathrm{~h}$. In addition, Lavraud et al. [2006] demonstrathe importance of the time-history of the system with respect to plasma conditions at GEO by $\mathrm{D}$ ning the build up of cold, dense plasma during extended periods of northwards IMF. Our aimstexplore inclusion of both of these effects in future versions of the model.

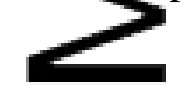

With regard to operational uses of the model, Thomsen et al. [2013] demonstrated that satellite surface charging Sty pngly correlated with periods when the electron flux at energies between 5-10 keV exceeds a narticular threshold. That study found that satellite surface charging was most likely to occur during intervals when the electron flux at $8 \mathrm{keV}$ exceeded a flux threshold of $1.4 \times 10^{3} \mathrm{~cm}^{-2} \mathrm{~s}^{-1}$ $\mathrm{str}^{-1} \mathrm{eV}^{-1}$ with this knowledge, one possible use of the model would be to: (i) determine appropriate cross-calibration factors between the model (based on MPA) and fluxes measured by the 
chosen satellite; (ii) use upstream values of solar-wind electric field to search for intervals when the predicted electron fluxes at $8 \mathrm{keV}$ exceeded a flux threshold; (iii) expect elevated surface charging to be more likely during such intervals.

The mode wrosides good agreement with in-sample MPA observations and (with appropriate on-orbit AMC-12. (t is hoped that the model will prove useful to the community of orbital hardware designers and satelliwerators, as well as to the scientific community who use fluxes at GEO as inputs to physical models.

In summat

(ర)

1. A new of the electron fluxes and ion fluxes at GEO, which uses the solar-wind electric field as input, rasten developed. The model provides a $\sim 1$ hour advanced forecast of the fluxes at GEO in the energyrange $\sim 1 \mathrm{eV}$ to $\sim 40 \mathrm{keV}$.

O

2. The model nrovides forecasts of the fluxes at GEO that are comparable in accuracy to the previous model, driven by the Kp index. The main benefit from the new model is the ability to predict the fluxes in adrance.

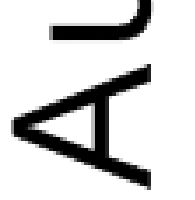


3. The model results are robust, during both quiet times and highly disturbed storm-times, as measured by the Root-Mean-Squared-Deviation (RMSD) and the Normalized Root-Mean-Squared Deviation (NRMSD). Observed fluxes are found to almost always fall between the 5th and 95th percentiles of the model-preaictions.

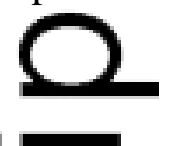

4. A new forecasting capability for spacecraft surface charging on the LANL satellites is introduced. Further de elopment of this capability is planned for the future.

\section{( )}

The model is freely available to users under the GNU General Public License v3.0 by contacting the author directly or via the model webpage at http://gemelli.spacescience.org/mdenton/.

\section{Acknowforements}

The authors gratefully acknowledge the OMNI database for the solar wind and geophysical parameters used in this study. We also acknowledge use of the list of satellites at GEO maintained by Eric Johnston www.satsig.net. This work was partially supported by the Space Hazards Induced near Earth by Carg, Dynamic Storms (SHIELDS) project, funded by the U.S. Department of Energy through thenL/LDRD Program under contract DE-AC52-06NA25396. MHD wishes to thank J. Denton for help with the Kp version of the model and comments on the current manuscript. MPA data are availabre of contacting the PI, Mike Henderson, at mghenderson@lanl.gov. The model, written in FORTRAN available from MHD at mdenton@spacescience.org, or via download at 
http://gemelli.spacescience.org/mdenton/ .

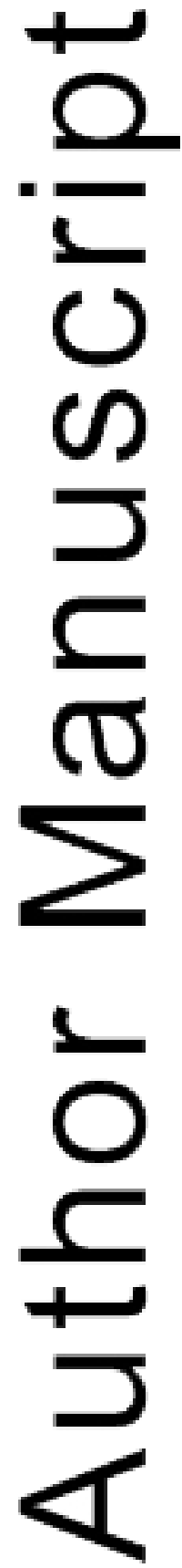

This article is protected by copyright. All rights reserved. 


\section{References}

Bame, S. J., D. J. McComas, M. F. Thomsen, B. L. Barraclough, R. C. Elphic, J. P. Glore, J. C. Chavez, E. P. Evans and F. J. Wymer, Rev. Sci. Instrum., 64, 1026-1033, 1993.

Bartels, J., N. A. H. Heck, and H. F. Johnstone, The three-hour-range index measuring geomagnetic activity, J. orophys. Res., 44, 411-454, 1939.

-

Borovsky J. E. Physical improvements to the solar wind reconnection control function for the Earth's magn tosp here, J. Geophys. Res. Space Physics, 118, 2113-2121, 2013.

Borovsky P. Canonical correlation analysis of the combined solar wind and geomagnetic index data sets, Joghys. Res. Space Physics, 119, 5364-5381, 2014.

DeForest, S.E. Spacecraft charging at synchronous orbit, J. Geophys. Res., 77, 651-659, 1972.

Denton, M. F., M. F. Thomsen, V. K. Jordanova, M. G. Henderson, J. E. Borovsky, J. S. Denton, D. Pitchbruand D. P. Hartley, An empirical model of electron and ion fluxes derived from observatigns at geosynchronous orbit, Space Weather, 13, 2015.

Denton, M. H., and J. E. Borovsky, Magnetosphere response to high-speed solar-wind streams: A complrison of weak and strong driving and the importance of extended periods of fast solar wind, J. Ge phy Res., 117, A00L05, doi:10.1029/2011JA017124, 2012.

Denton, $\mathrm{Y}$, and J. E. Borovksy, The superdense plasma sheet in the magnetosphere during highspeed-stream-driven storms: Plasma transport timescalesJ. Atmos. Sol-Terr. Phys, 71, 1045-1058, 2009

Denton, M. ب. M. F. Thomsen, B. Lavraud, M. G. Henderson, R. M. Skoug, H. O. Funsten, J.-M. 
Jahn, C. J. Pollock, and J. M. Weygand, Transport of plasma sheet material to the inner magnetosphere, Geophys. Res. Lett., 34, L04105, doi:10.1029/2006GL027886, 2007.

Denton, M. H., M. F. Thomsen, H. Korth, S. Lynch, J. C. Zhang and M. W. Liemohn, Bulk plasma properties at geosynchronous orbit, J. Geophys. Res., 110, A07223, 2005.

Dichter, R. McGarity, M. R. Oberhardt, V. T. Jordanov, D. J. Sperry, A. C. Huber, J. A. Pantacis, E. G. Mullen, G. Ginet, and M. S. Gussenhoven, Compact Environmental Anomaly Sens (GEASE): A novel spacecraft instrument for in situ measurements of environmental condition IEEE Trans. Nucl. Sci., 45, 2758-2764, 1998.

Farthing, 느, J. P. Brown, and W. C. Bryant, Differential spacecraft charging on the geostationary operational satellites, NASA Tech. Memo, NASA TM-83908, 1982.

Ganushkim Y., O. A. Amariutei, D. Welling, and D. Heynderickx, Nowcast model for low-energy electrif the inner magnetosphere, Space Weather, 13, 16-34, doi:10.1002/2014SW001098, 20

Ganush Y., M. W. Liemohn, O. A. Amariutei, and D. Pitchford, Low-energy electrons (5-50 $\mathrm{keV)}$ in the inner magnetosphere, J. Geophys. Res. Space Physics, 119, 246-259, doi:10109/2013JA019304, 2014.

Ganushkina_ $\_$Y., O. Amariutei, Y. Y. Shpritz, and M. Liemohn, Transport of the plasma sheet electrons to the geostationary distances, J. Geophys. Res. Space Physics, 118, 82-98, doi:1012012JA017923, 2013.

Garrett, H. B..The charging of spacecraft surfaces, Rev. Geophys., 19, 577-616, 1981. 
Ginet, G. P., T. P. O’Brien, S. L. Huston, W. R. Johnston, T. B. Guild, R. Friedel, C. D. Lindstrom, C. J. Roth, P. Whelan, R. A. Quinn, D. Madden, S. Morley, and Yi-Jiun Su, AE9, AP9 and SPM: New Models for Specifying the Trapped Energetic Particle and Space Plasma Environment, in The Vantilen Probes mission, eds N. Fox and J. L. Burch, Springer, doi:10.1007/978-1-4899-7433-4, ISBN 070 1899-7432-7, 2014.

Hartley, r. P., M. H. Denton, and J. V. Rodriguez, Electron number density, temperature, and energy densi al GEO and links to the solar wind: A simple predictive capability, J. Geophys. Res. Space Physigs, 9, 4556-4571, doi:10.1002/2014JA019779, 2014.

Jordanova V K., C. J. Farrugia, L. Janoo, J. M. Quinn, R. B. Torbert, K. W. Ogilvie, R. P. Lepping, J. T. Steinberg, D. J. McComas, and R. D. Belian, October 1995 magnetic cloud and accompanying storm imity: Ring current evolution, J. Geophys. Res., 103, 79, 1998.

Jordanovd. L., L. M. Kistler, M. F. Thomsen, and C. G. Mouikis, Effects of plasma sheet variability on fast initial ring current decay, Geophys. Res. Lett., 30(6), 1311, doi.ro.ruz9/2002GL016576, 2003.

Katus, R.M., M. W. Liemohn, E. L. Ionides, R. Ilie, D. Welling, and L. K. Sarno-Smith, Statistical analy 5 of the geomagnetic response to different solar wind drivers and the dependence on storm intensity Geophys. Res., doi:10.1002/2014JA020712, 2014.

King, J. H., and N. E. Papitashvili, Solar wind spatial scales in and comparisons of hourly Wind and ACE

Koh, T.-Y. S.Wang, and B. C. Bhatt, A diagnostic suite to assess NWP performance, J. Geophys. 
Res., 2012, 117, D13109, 2012.

Korth, H., M. F. Thomsen, J. E. Borovsky, and D. J. McComas, Plasma sheet access to geosynchronous orbit, J. Geophys. Res., 104, 25,047-25,061, 1999.

Lanzerott, L. J., C. Breglia, D. W. Maurer, G. K. Johnson III, and C. G. MacLennan, Studies of space arestarging on a geosynchronous telecommunications satellite, Adv. Space Res., 22, 79$82,1998$.

Lavraud, (․, M. F. Thomsen, J. E. Borovsky, M. H. Denton, and T. I. Pulkkinen, Magnetosphere precopdiming under northward IMF: Evidence from the study of coronal mass ejection and corotatino interaction region geoeffectiveness, J. Geophys. Res., 111, A09208, doi:10.1029/2005JA011566, 2006.

Lavraud, H. Denton, M. F. Thomsen, J. E. Borovsky, and R. H. W. Friedel, Superposed epoch analy is of dense plasma access to geosynchronous orbit, Ann. Geophys., 23, 2519-2529, 2005.

Legates, and G. J. McCabe Jr., Evaluating the use of "goodness-of-fit" Measures in hydrologic and modroclimatic validation, Water Resour. Res., 35(1), 233-241, doi:10.1029/1998WR900018, 1999.

McPherro, T. T.-S. Hsu, and X. Chu, An optimum solar wind coupling function for the AL index. J. Geonhvs. Res. Space Physics, 120, 2494-2515, doi: 10.1002/2014JA020619, 2015.

Newell, magnere coupling function inferred from 10 magnetospheric state variables, J. Geophys. Res., 112,A01206, doi:10.1029/2006JA012015, 2007. 
O’Brien, T. P., J. E. Mazur, and J. F. Fennell, The Priority Mismatch Between Space Science and Satellite Operations, Space Weather, 11, doi:10.1002/swe.20028, 2013

O’Brien, T. P., SEAES-GEO: A spacecraft environmental anomalies expert system for geosyncnronous orbit, Space Weather, 7, S09003, 2009.

O'Brien, P. Lemon, Reanalysis of plasma measurements at geosynchronous orbit, Space Weather, 5, S03007, doi:10.1029/2006SW000279, 2007.

Purvis, C K., H. B. Garrett, A. C. Whittlesey, and N. J. Stevens, Design guidelines for assessing and contrdlims spacecraft charging effects, NASA Tech. Pap. 2361, 1984.

Sicard-Piet_SS. Bourdarie, D. Boscher, R. H. W. Friedel, M. Thomsen, T. Goka, H. Matsumoto, and H. Koshishi, A new international geostationary electron model: IGE-2006, from 1 keV to 5.2 MeVeather, 6, S07003, doi:10.1029/2007SW000368, 2008.

Thomsen, M. M. G. Henderson, and V. K. Jordanova, Statistical properties of the surface-charging envirament at geosynchronous orbit, Space Weather, 11, 237-244, 2013.

Thomsen, F., E. Noveroske, J. E. Borovsky, and D. J. McComas, Calculating the Moments from Measurements by the Los Alamos Magnetospheric Plasma Analyzer, LA-13566-MS, Los Alamos Natio angaboratory, 1999.

Thomsen, ME., Why Kp is such a good measure of magnetospheric convection, Space Weather, 2, S1 I004, döi:10.1029/2004SW000089, 2004.

Thomsen, F., M. H. Denton, B. Lavraud, and M. Bodeau, Statistics of plasma fluxes at geosynchronous orbit over more than a full solar cycle, Space Weather, 5, S03004, 
doi:10.1029/2006SW000257, 2007.

Zaharia, S., M. F. Thomsen, J. Birn, M. H. Denton, V. K. Jordanova, and C. Z. Cheng, Effect of stormtime plasma pressure on the magnetic field in the inner magnetosphere, Geophys. Res. Lett., 32, L031U2, doi:10.1029/2004GL021491, 2005.

Zaharia, S fieldsand plasmas in the inner magnetosphere: Application to a geomagnetic storm, J. Geophys. Res., 11,411S14, doi:10.1029/2006JA011619, 2006.

()
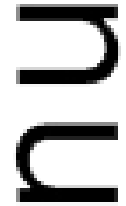

চে
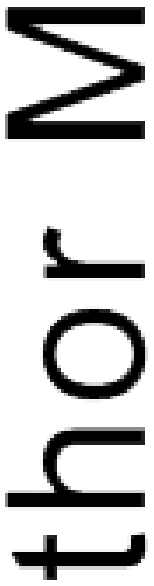

安 


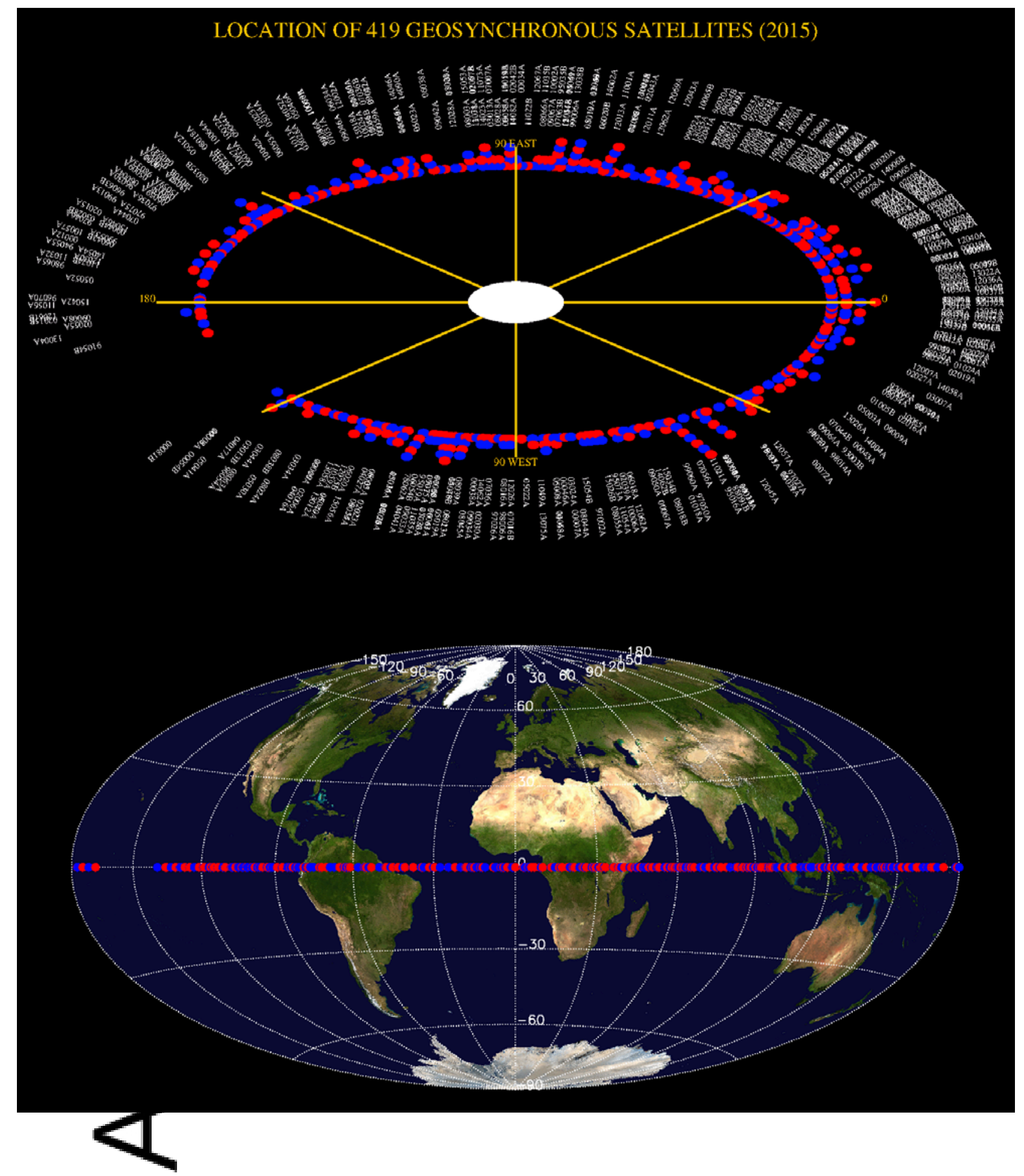

This article is protected by copyright. All rights reserved. 
Figure 1. (Top panel) The geographic (equatorial) locations of selected Earth-orbiting satellites located in a synchronous orbit east and west of the Greenwich meridian $\left(0^{\circ}\right.$ longitude). Where more than one satellite is located at the same longitude (to 0.1 degree accuracy) the satellites are displayed radially outwards from GEO. (Bottom panel) The geographic equatorial footprint of the satellites on the Earth (Hammer-Aitoff projection). Note: no account is taken of the satellite inclination. Adjacent satellites are alternately displayed in red/blue for clarity.

\section{Binning Scheme for $-\mathrm{vB}_{\mathrm{z}}$ Model}

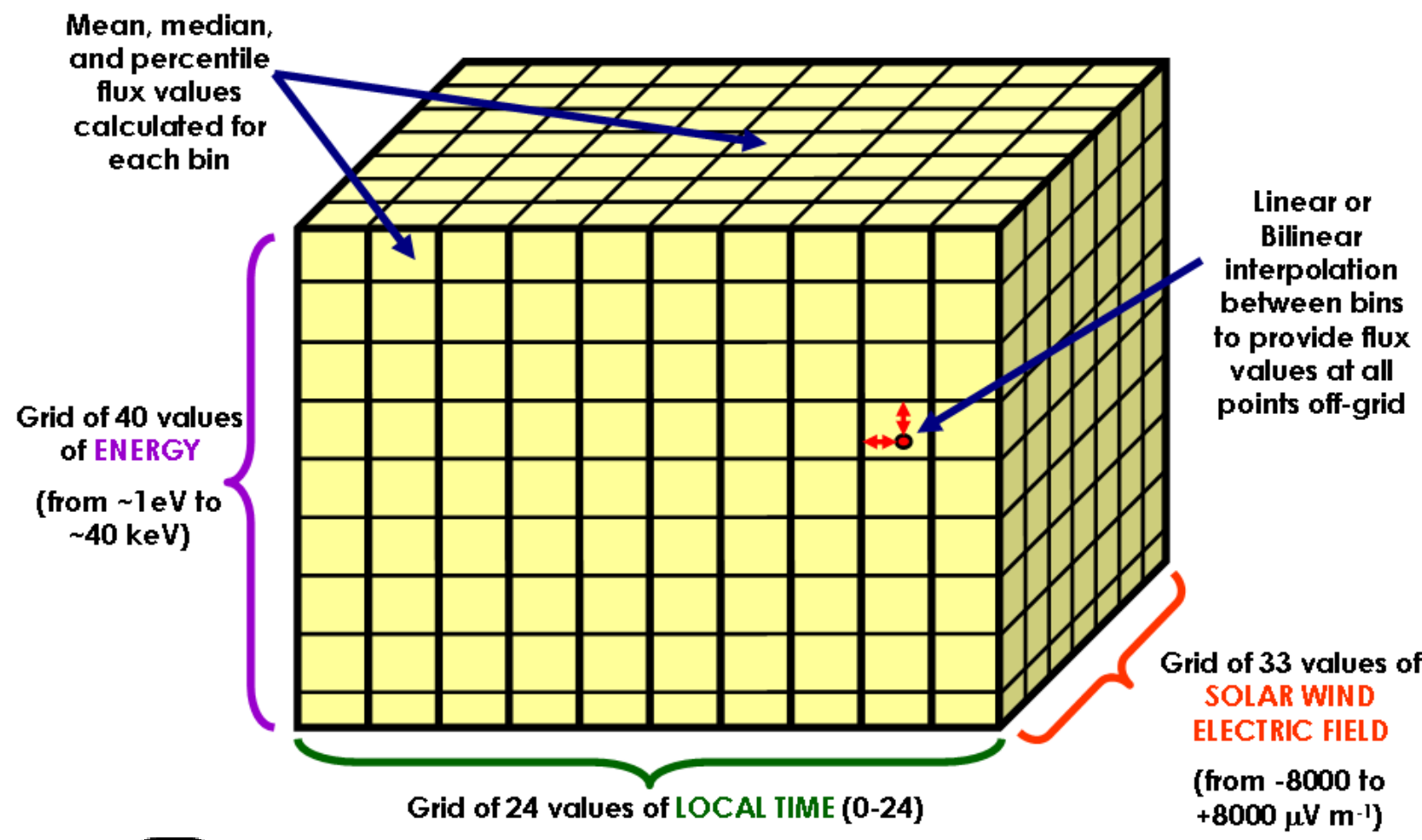

Figure 2. Coldematic showing the binning scheme for the $-\mathrm{vB}_{\mathrm{z}}$ model. The three-dimensional model grid contain energy bins (between $1 \mathrm{eV}$ and $40 \mathrm{keV}$ ), 33 bins of $-\mathrm{vB}_{\mathrm{z}}$ values $(-8000$ to +8000$)$, and 24 bins of local time (0-24), for both the ions and the electrons. 


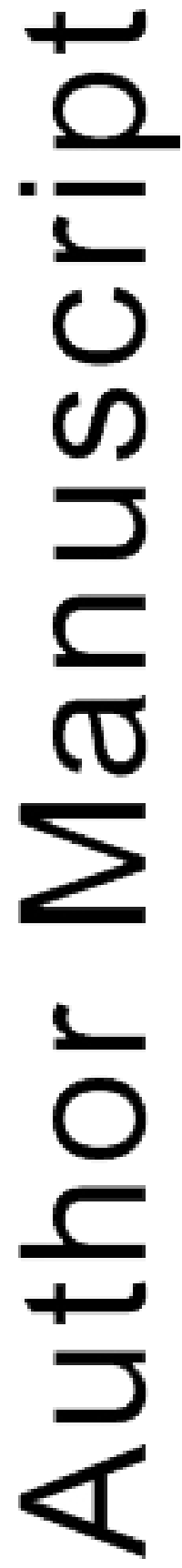

This article is protected by copyright. All rights reserved. 

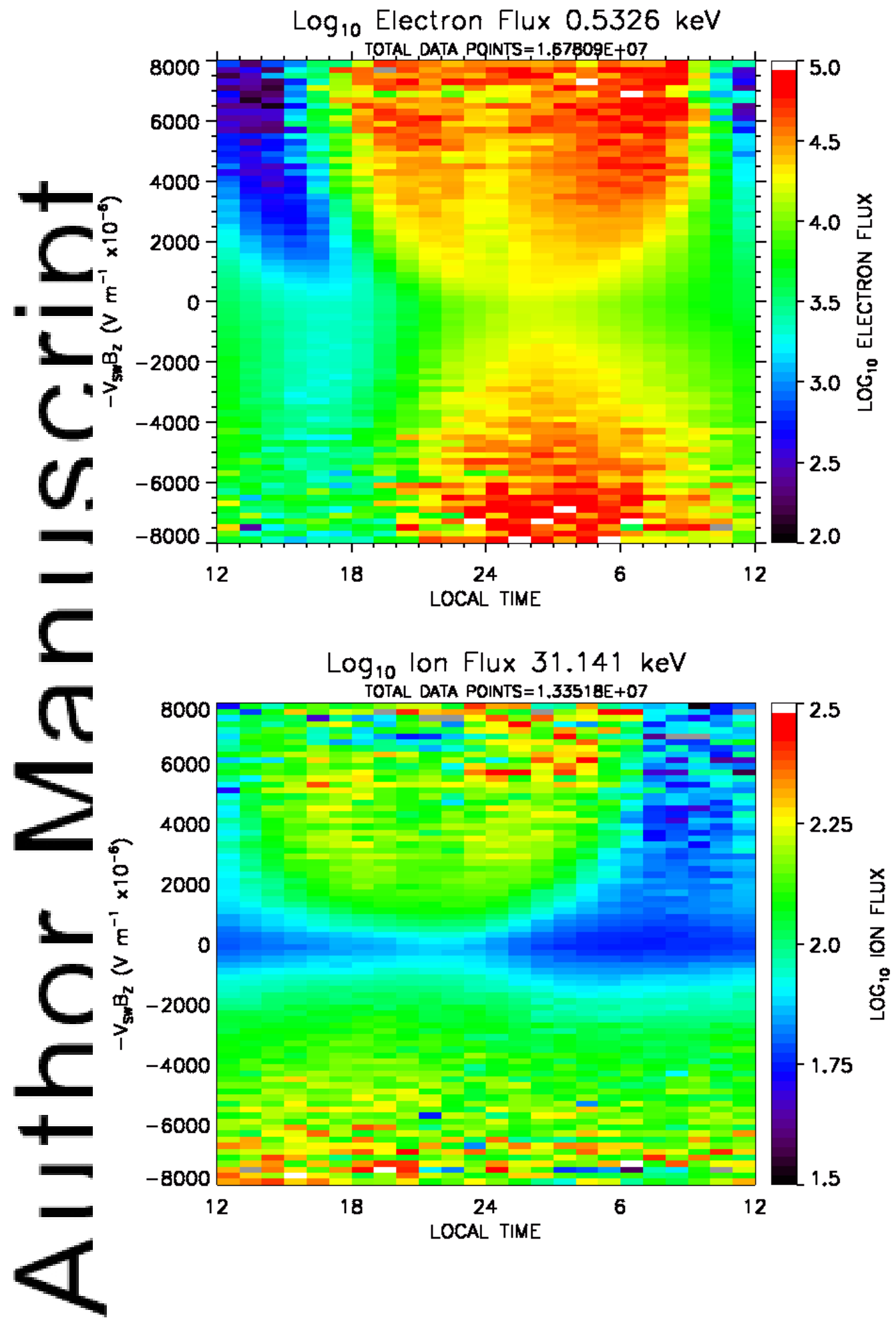

This article is protected by copyright. All rights reserved. 
Figure 3. Example mean fluxes from LANL/MPA as a function of solar-wind electric field and local time, for the electrons (top panel - 532.6 eV) and the ions (bottom panel - $31141 \mathrm{eV}$ ). These plots demonstrate the large difference in the average flux at GEO for cases where the IMF is northwards (negative $-\mathrm{v}_{\mathrm{sw}} \mathrm{B}_{\mathrm{z}}$ ) or southwards (positive $-\mathrm{v}_{\mathrm{sw}} \mathrm{B}_{\mathrm{z}}$ ).

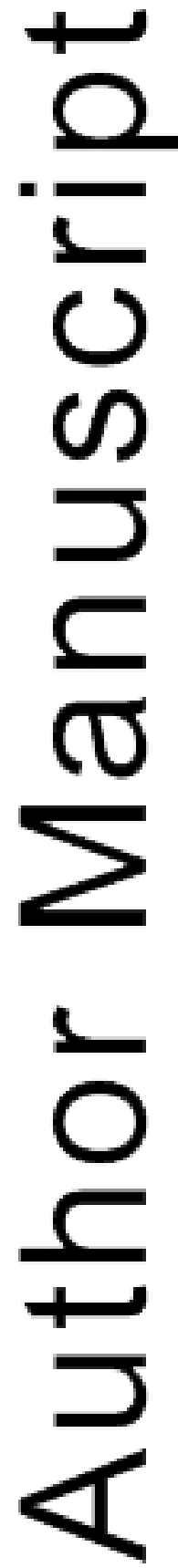

This article is protected by copyright. All rights reserved. 


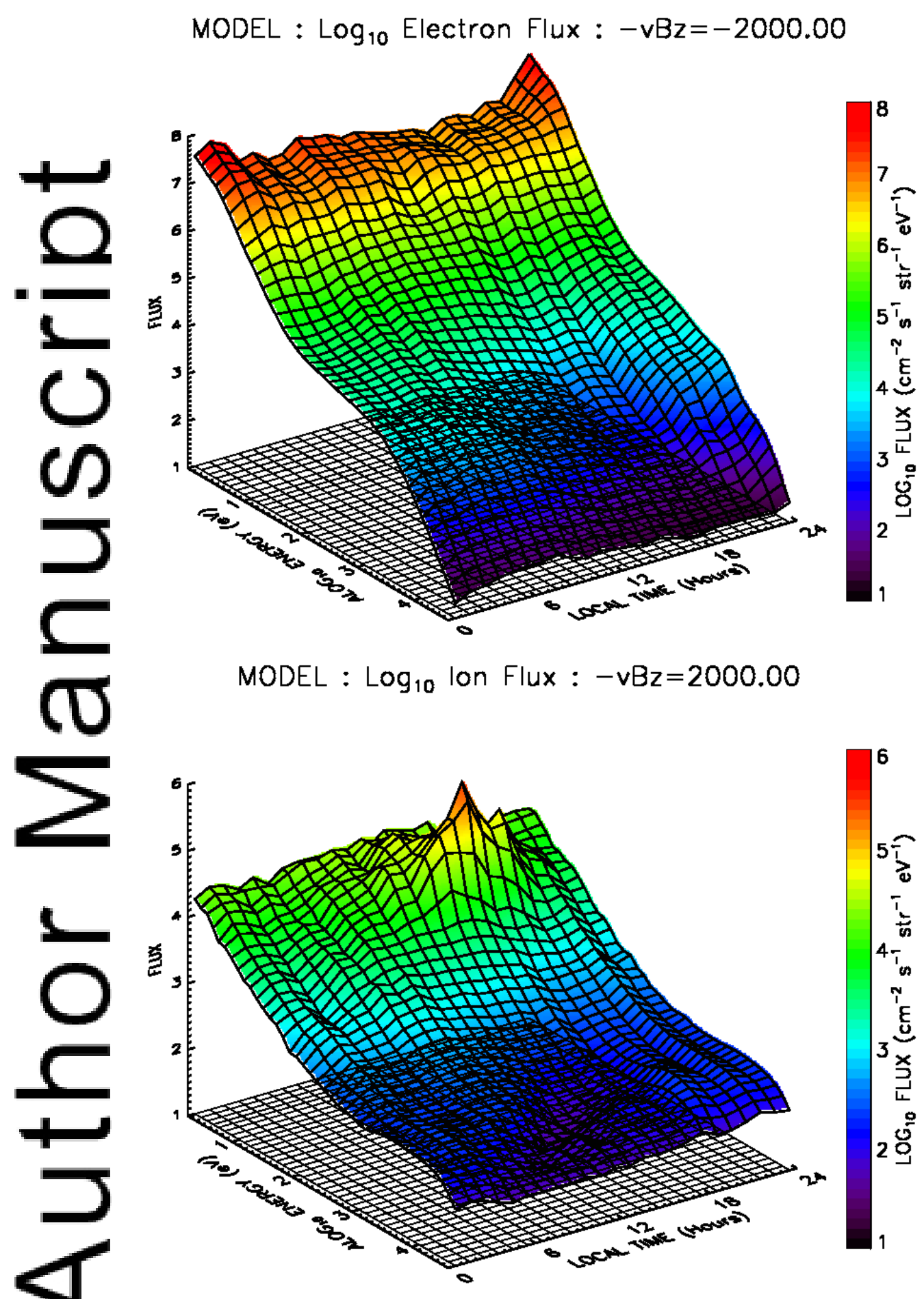

This article is protected by copyright. All rights reserved. 
Figure 4. Example surfaces showing the model flux surfaces at two different values of $-\mathrm{v}_{\mathrm{sw}} \mathrm{B}_{\mathrm{z}}$, for electrons (top: $-\mathrm{vB}_{\mathrm{z}}=2000 \mu \mathrm{V} \mathrm{m}^{-1}$.) and ions (bottom: $-\mathrm{vB}_{\mathrm{z}}=-2000 \mu \mathrm{V} \mathrm{m}{ }^{-1}$ ), as a function of energy and local time. Flux values at points off the grid can be computed via bi-linear interpolation between grid points, and subsequent linear interpolation between the discrete values of $-\mathrm{v}_{\mathrm{sw}} \mathrm{B}_{\mathrm{z}}$.

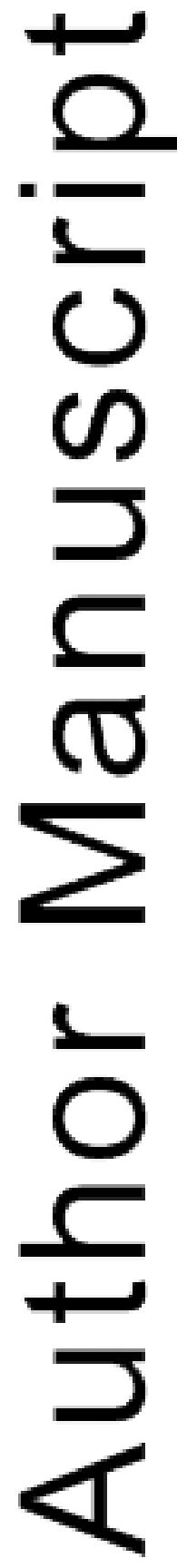

This article is protected by copyright. All rights reserved. 

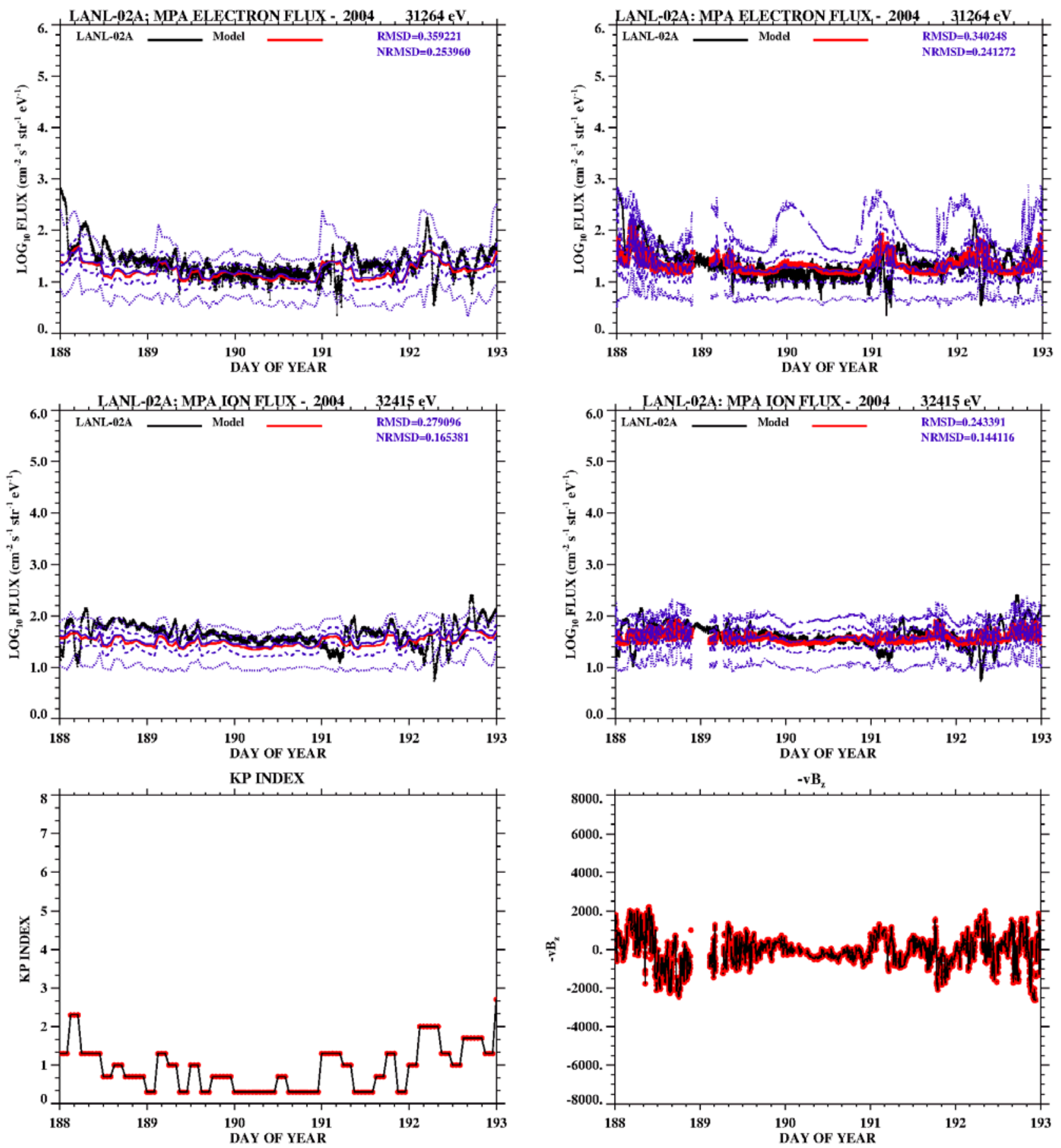

Figure rample model results for five very calm days in 2004 for electrons and ions with energies

This article is protected by copyright. All rights reserved. 
$\sim 32 \mathrm{keV}$. The left column shows the model predictions for electrons and ions using the Kp version of the model. The right column shows model predictions in the same format, but using the $-\mathrm{v}_{\mathrm{sw}} \mathrm{B}_{\mathrm{z}}$ version of the model. The black line shows the observations from the LANL-02A satellite. The solid red line is the predicted mean flux, and the solid purple line is the median. The 5th, 25th, 75th and 95th percentiles are indicated by the dashed and dotted purple lines. The Kp index and the $-\mathrm{v}_{\mathrm{sw}} \mathrm{B}_{\mathrm{z}}$ parameter are also shown in the bottom row.

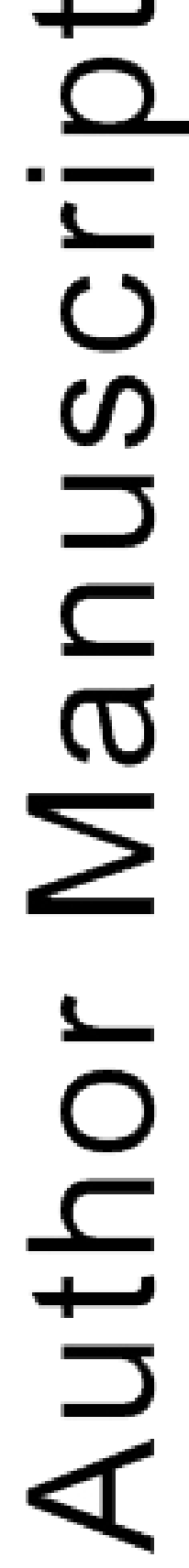



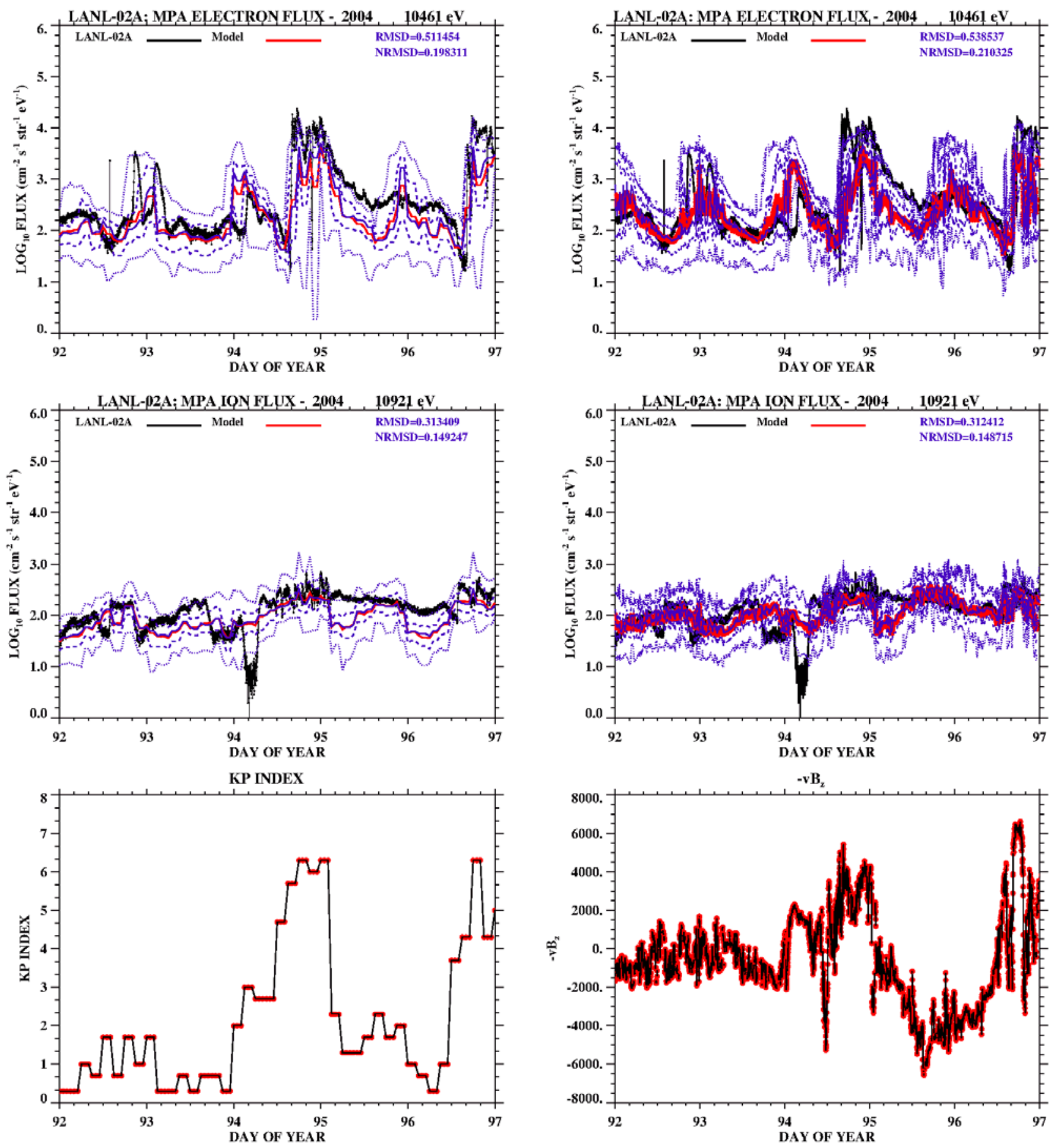

Figure 1 kample model results for five disturbed days in 2004 for electrons and ions with energies

This article is protected by copyright. All rights reserved. 
$\sim 10 \mathrm{keV}$. The left column shows the model predictions for electrons and ions using the Kp version of the model. The right column shows model predictions in the same format, but using the $-\mathrm{v}_{\mathrm{sw}} \mathrm{B}_{\mathrm{z}}$ version of the model. The black like shows the observations from the LANL-02A satellite. The solid red line is the predicted mean flux, and the solid purple line is the median. The 5th, 25th, 75th and 95th percentiles are indicated by the dashed and dotted purple lines. The Kp index and the $-\mathrm{v}_{\mathrm{sw}} \mathrm{B}_{\mathrm{z}}$ parameter are also shown in the bottom row.

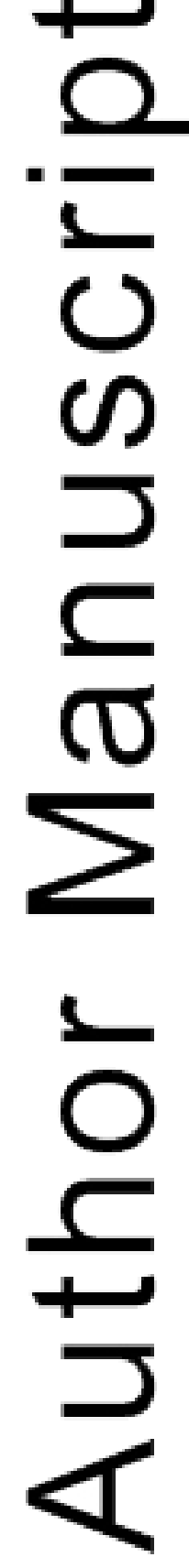




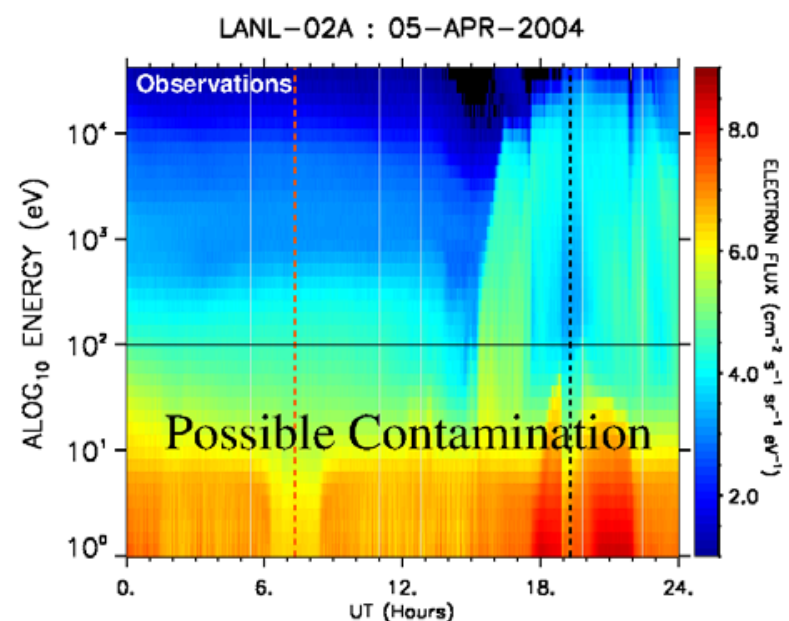

ELECTRON FLUX MODEL : 2004/096

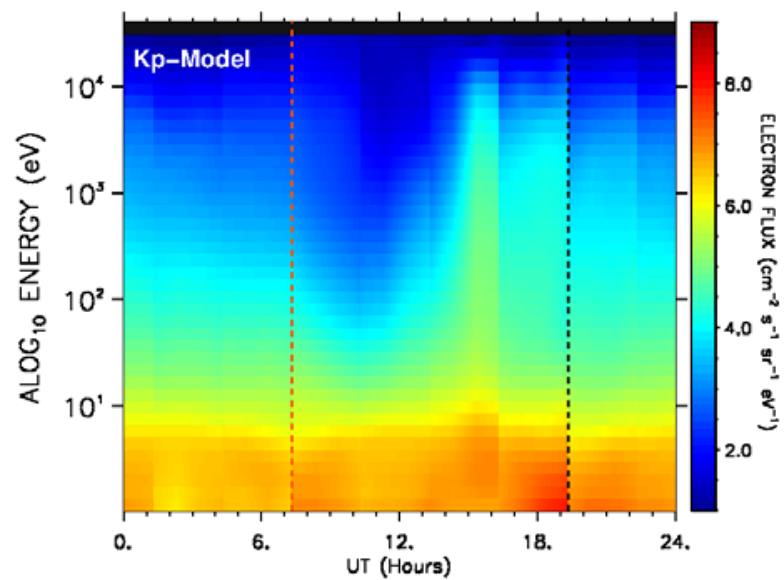

ELECTRON FLUX MODEL : 2004/096

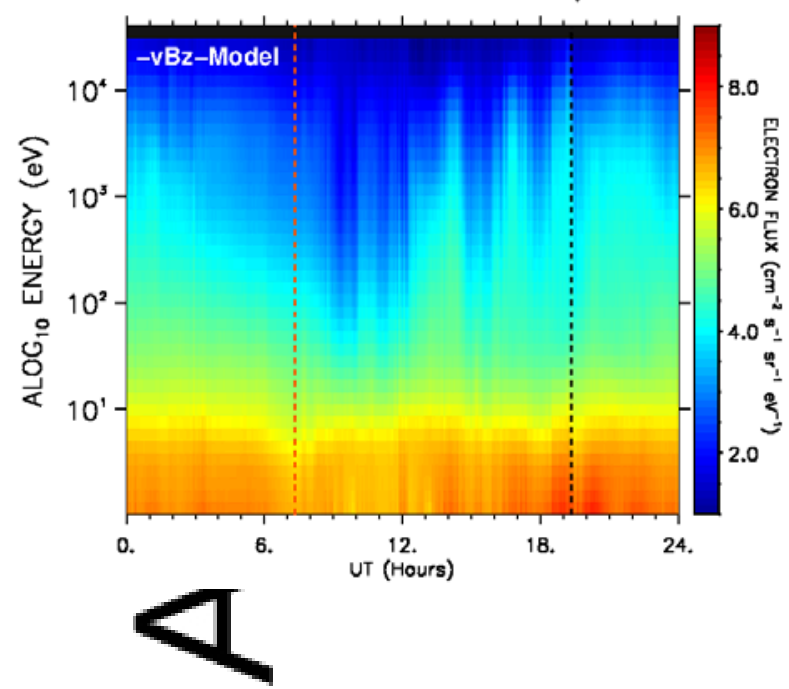

LANL-02A : 05-APR-2004

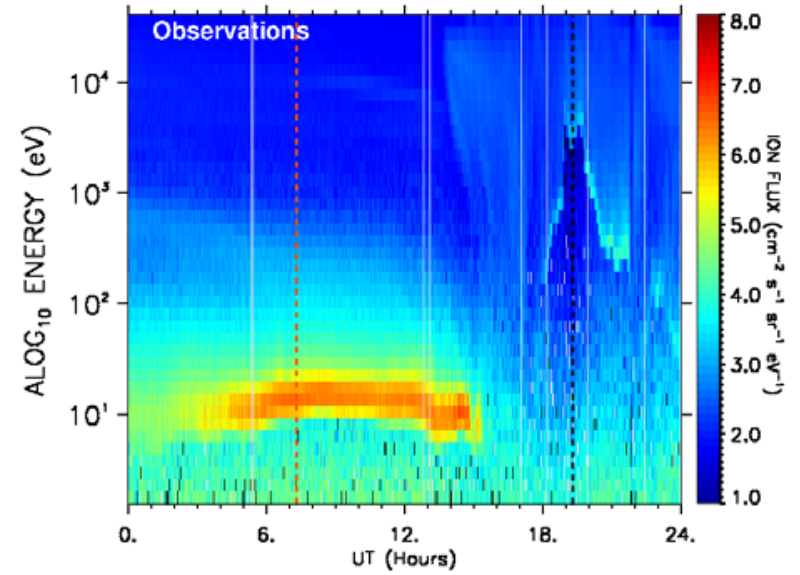

ION FLUX MODEL : 2004/096

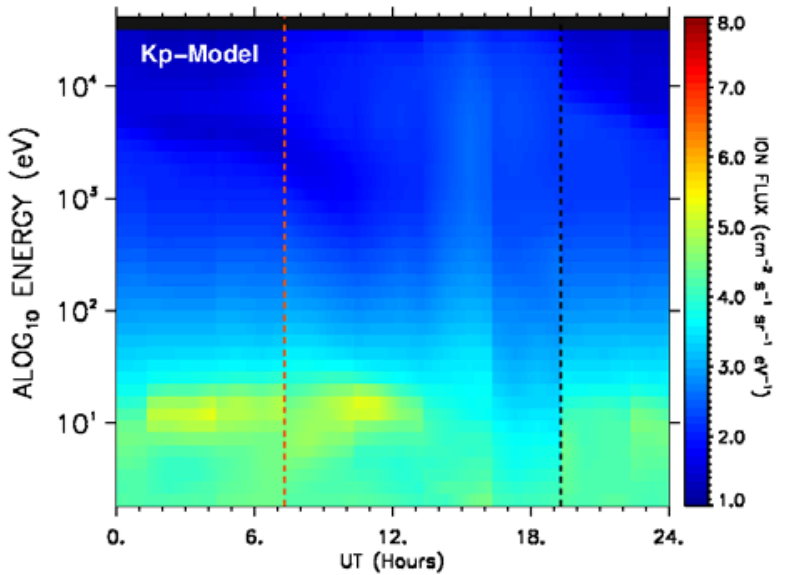

ION FLUX MODEL : 2004/096

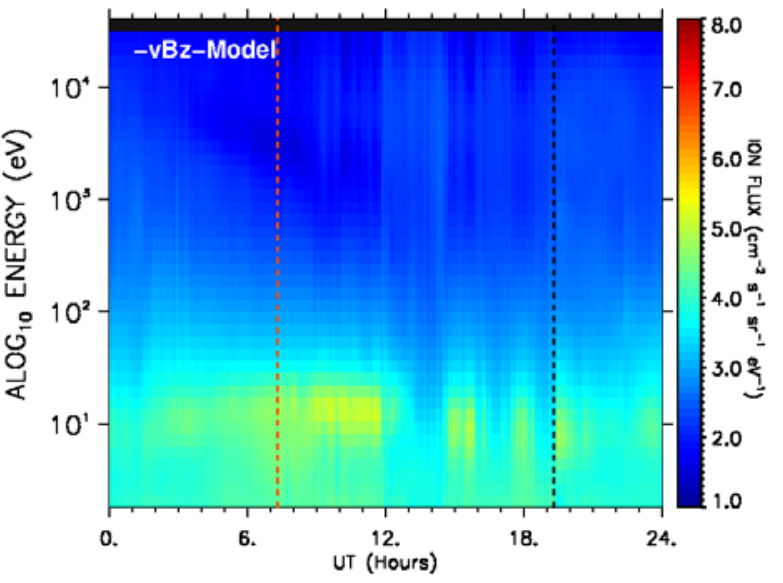


Figure 7. Comparison of particle flux observations (top row) with the Kp-model (middle row) and the new $-\mathrm{v}_{\mathrm{sw}} \mathrm{B}_{\mathrm{Z}}$ model (bottom row) for electrons (left column) and ions (right column) on 5th April (dayof-year 96) in 2004. Large fluctuations occur in both the $\mathrm{Kp}$ index and in the $-\mathrm{v}_{\mathrm{sw}} \mathrm{B}_{\mathrm{z}}$ parameter on this day (see Figure 6). The orange line marks local noon and the black line marks local midnight in each plot.

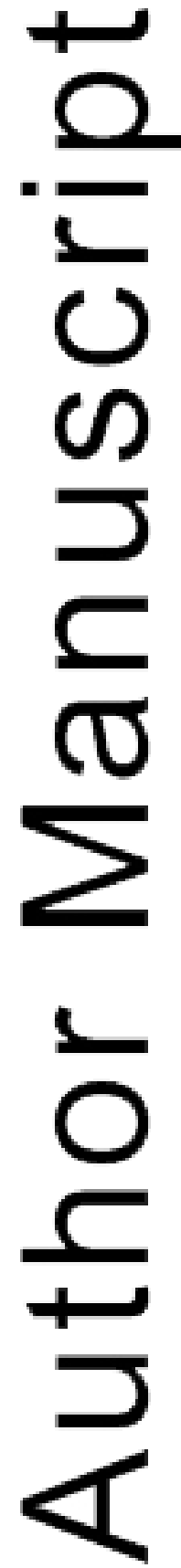



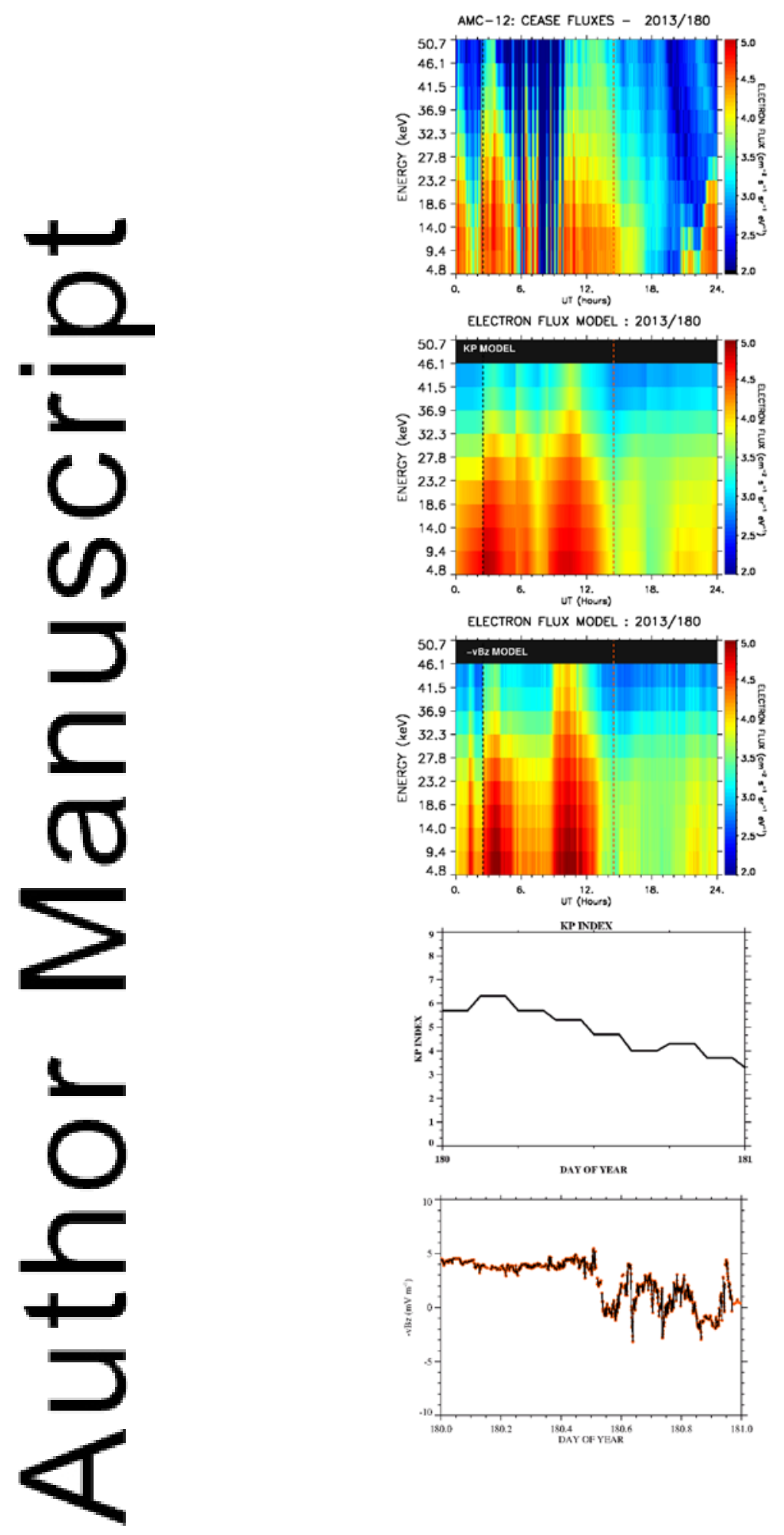

This article is protected by copyright. All rights reserved. 
Figure 8. Figure showing the CEASE-II electron flux observations from AMC-12 (top panel) on 29th June (DOY- 180) in 2013 during disturbed geomagnetic activity. Also shown are the electron flux predictions from the Kp model (middle panel), and the electron flux predictions from the $-\mathrm{v}_{\mathrm{sw}} \mathrm{B}_{\mathrm{z}}$ model (bottom panel). Note: the CEASE-II electron fluxes have been multiplied by a constant factor (crosscalibrated) to bring them into alignment with the LANL/MPA model fluxes. Kp and $-\mathrm{v}_{\mathrm{sw}} \mathrm{B}_{\mathrm{z}}$ are also shown.
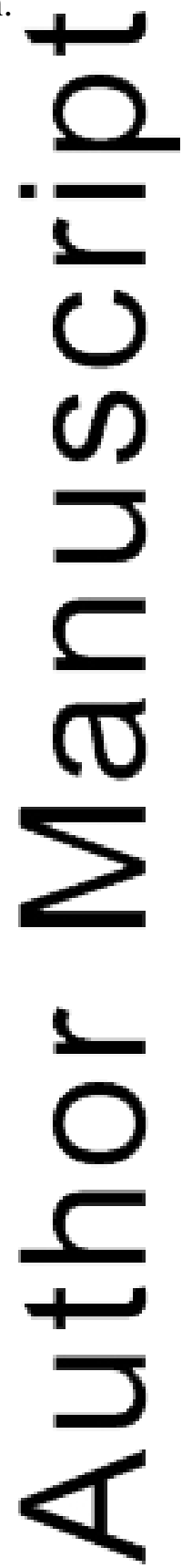


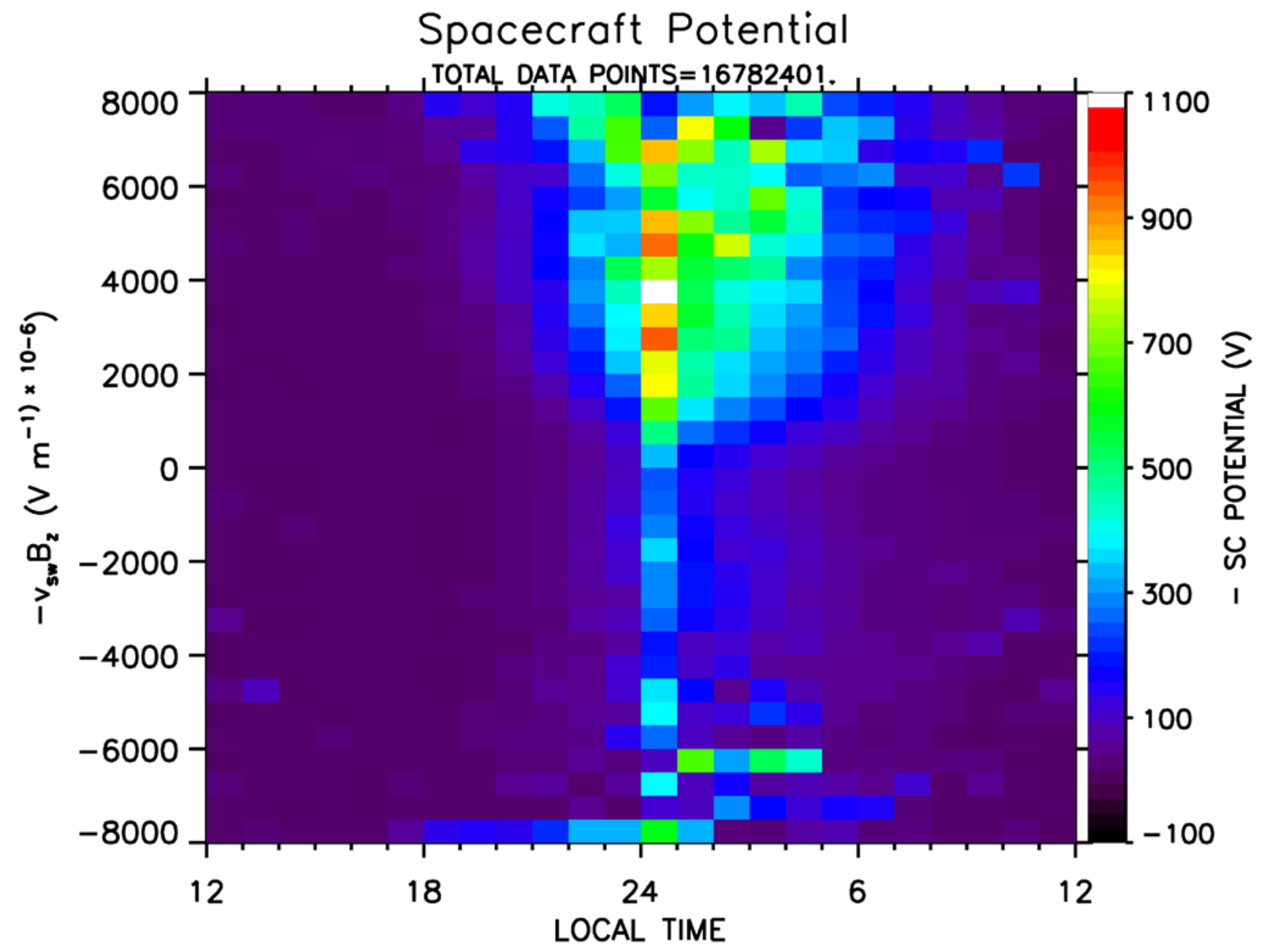

Figure 9. Sh wing the mean (negative) of the spacecraft potential measured by MPA spacecraft between 1990 and 2007 as a function of $-v_{s w} B_{z}$ and local time. The spacecraft surface potential is clearly mesterevated around local midnight, and during southwards excursions of IMF- $\mathrm{B}_{\mathrm{z}}$.

This article is protected by copyright. All rights reserved. 


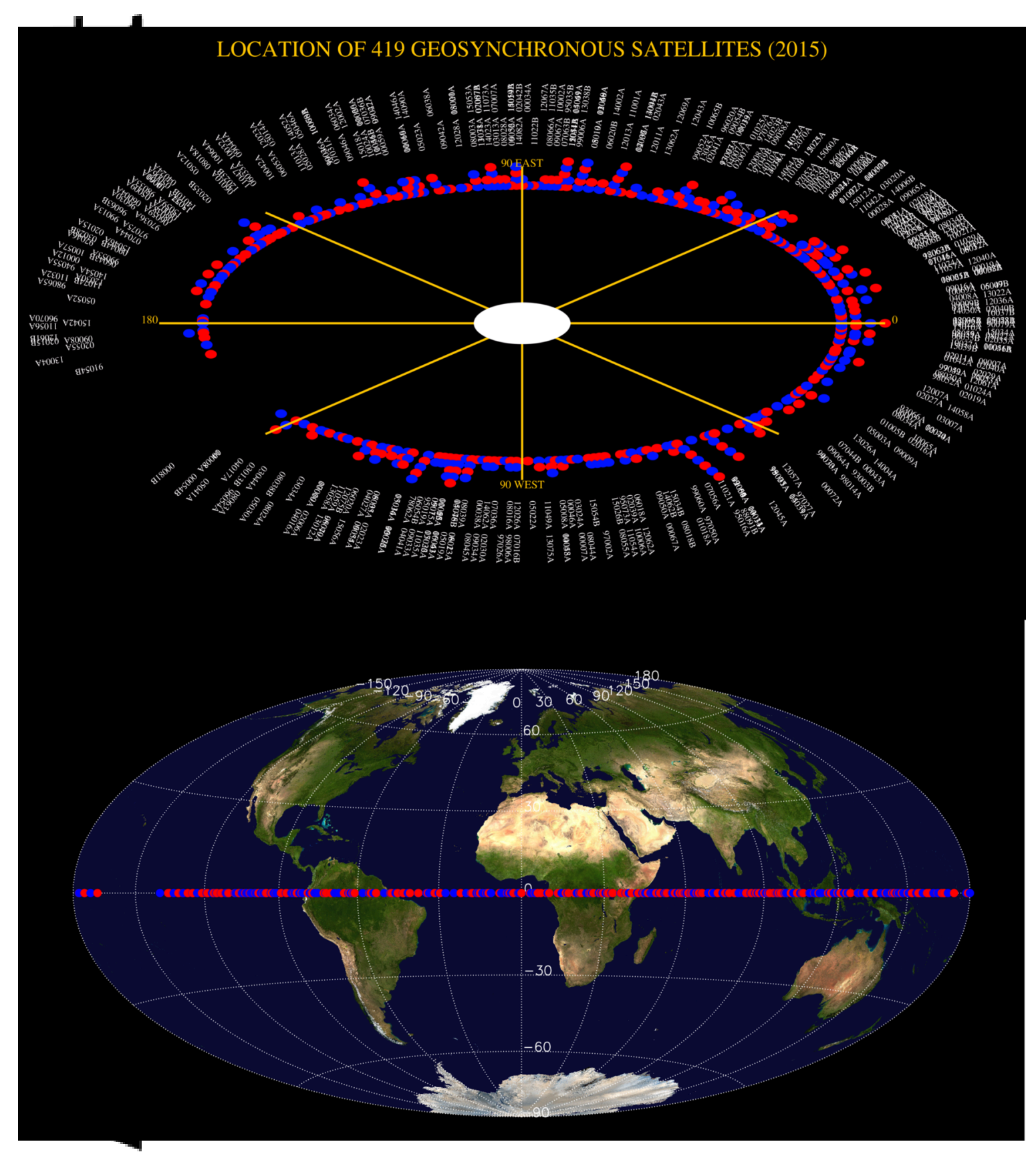

2016sw001409-f01-z-.eps

This article is protected by copyright. All rights reserved. 


\section{뭉 \\ Binning Scheme for $-\mathrm{vB}_{\mathrm{z}}$ Model}

Mean, median, and percentile

flux values calculated for each bin

Grid of $\mathbf{4 0}$ values of ENERGY

(from $\sim$ eV to $\sim 40 \mathrm{keV}$ )

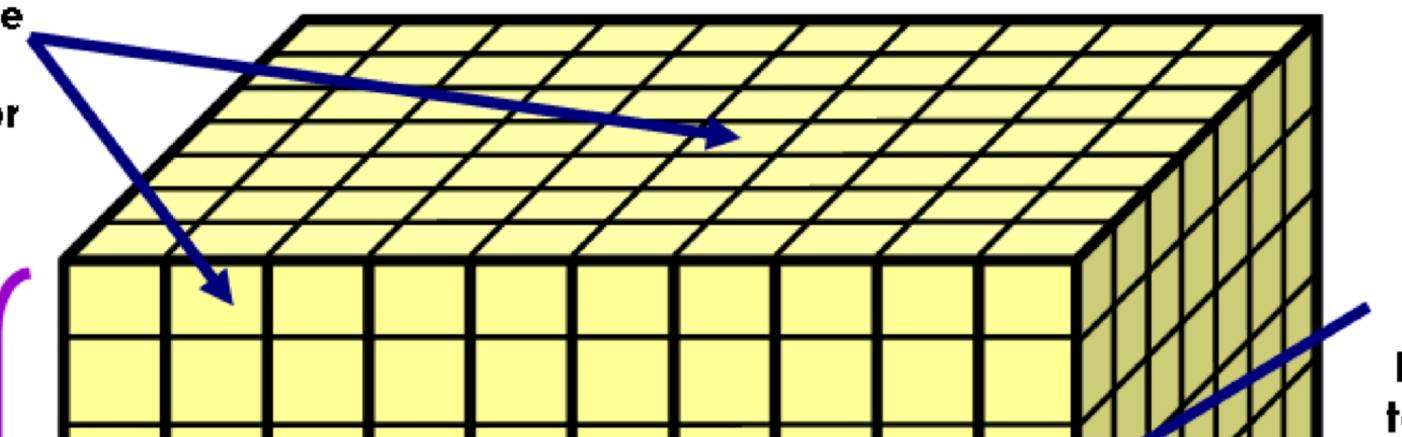

Linear or Bilinear interpolation between bins to provide flux values at all points off-grid

Grid of 24 values of LOCAL TIME (0-24)

Grid of 33 values of

SOLAR WIN D

ELECTRIC FIELD

(from -8000 to $+8000 \mu \mathrm{V} \mathrm{m}^{-1}$ )

2016sw001409-f02-z-.eps 


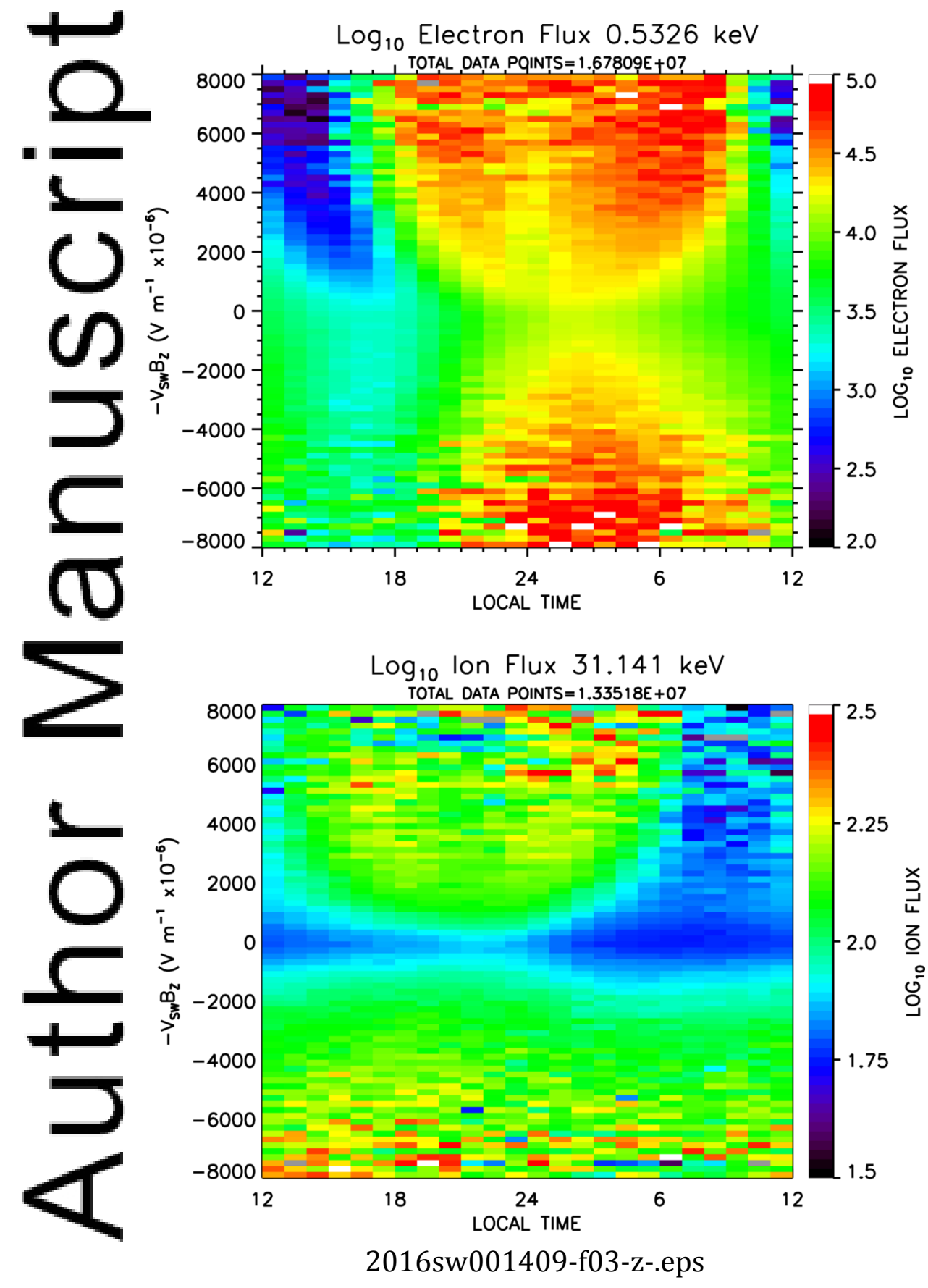

This article is protected by copyright. All rights reserved. 


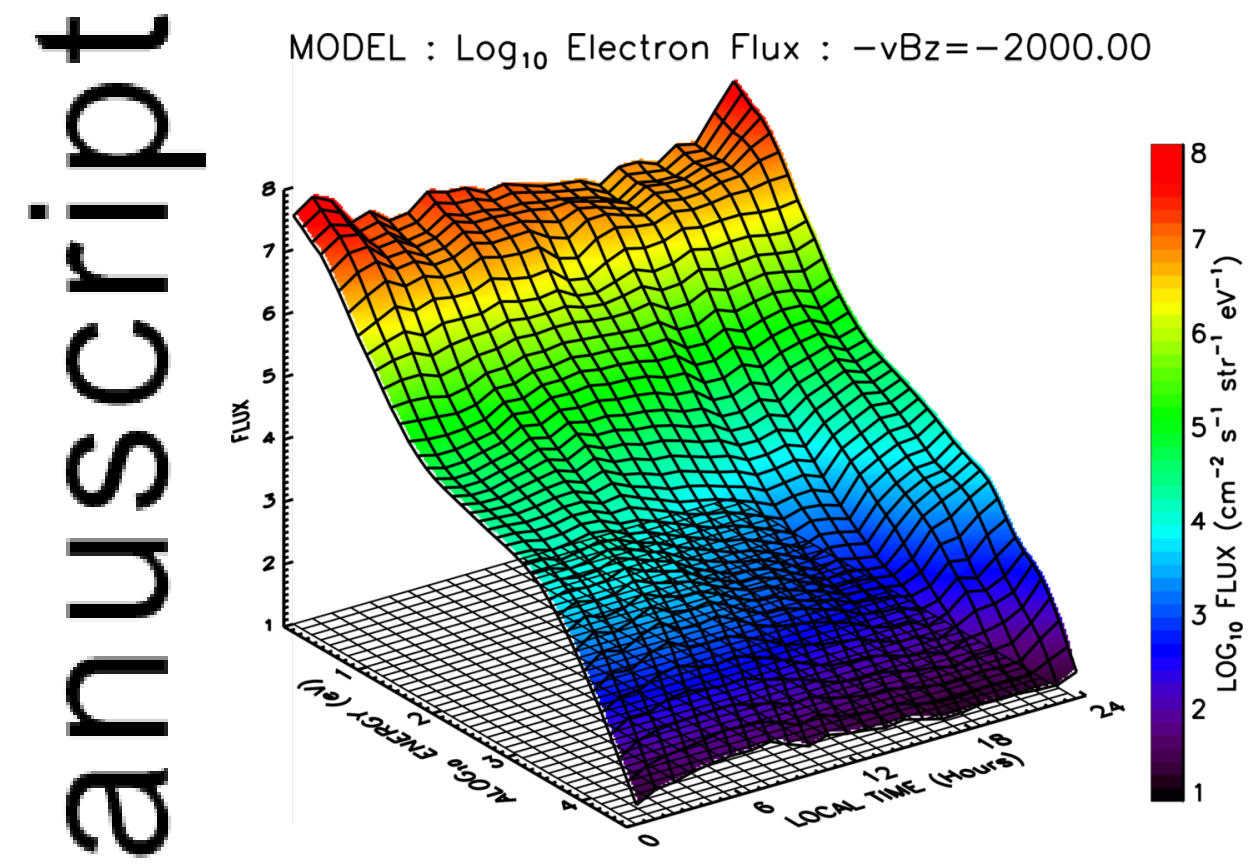

MODEL : $\log _{10}$ Ion Flux : $-v B z=2000.00$
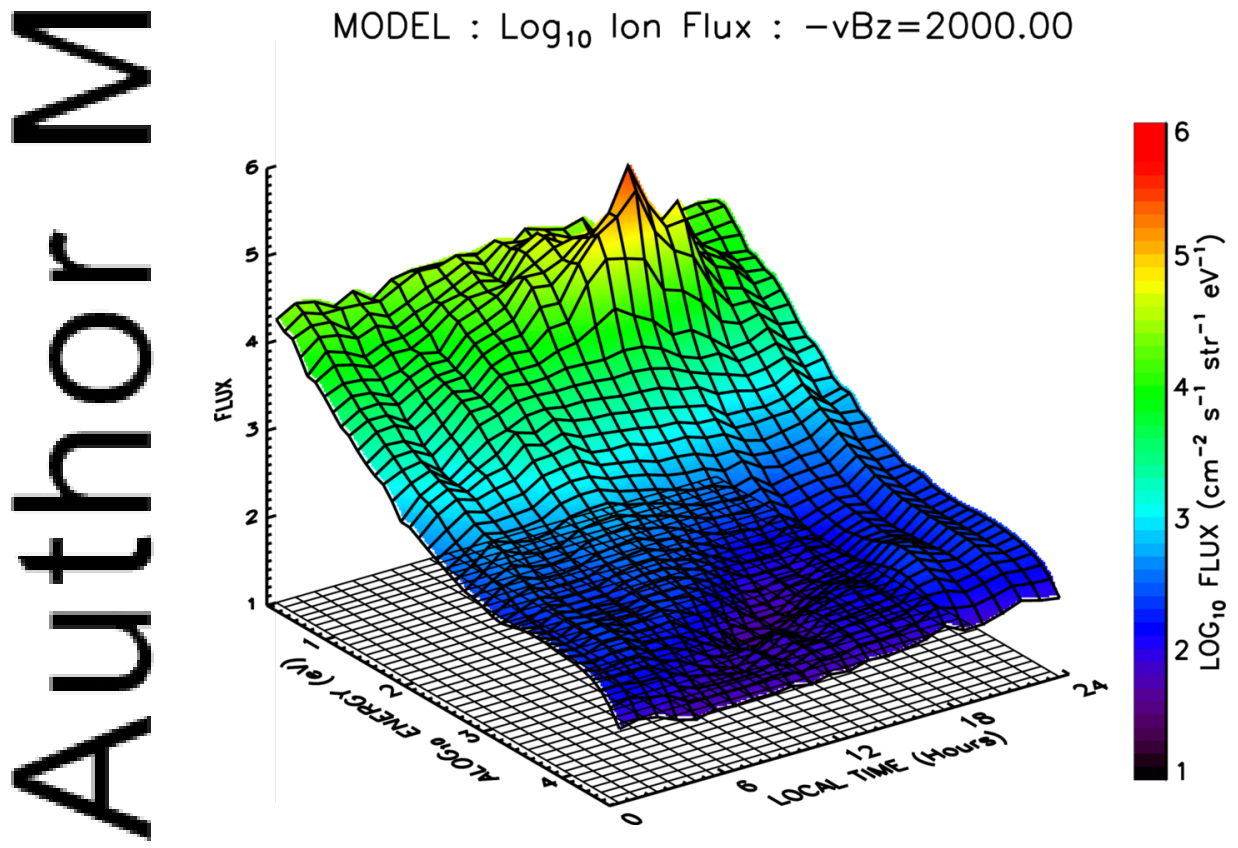

2016sw001409-f04-z-.eps 

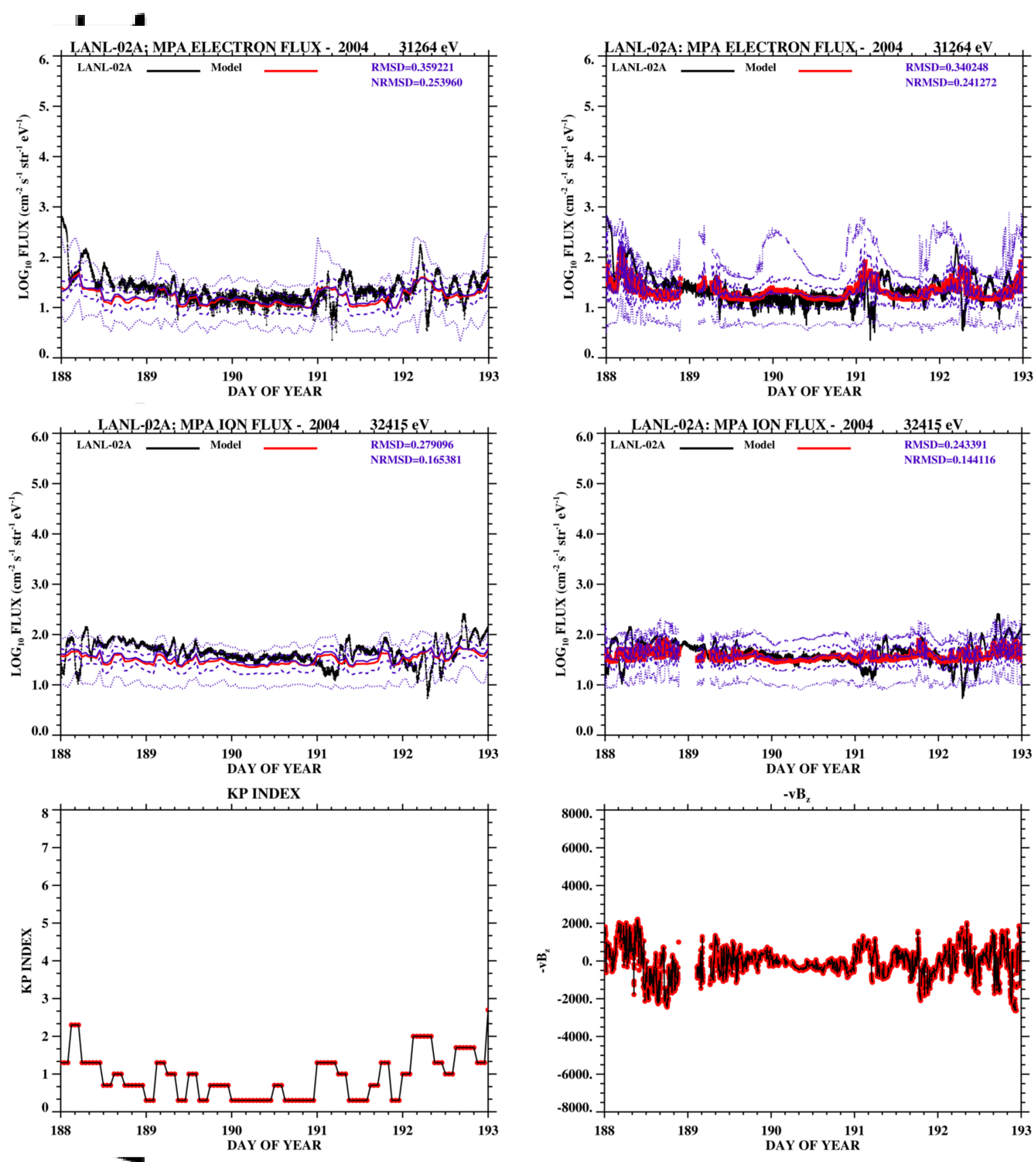

2016sw001409-f05-z-.eps

This article is protected by copyright. All rights reserved. 

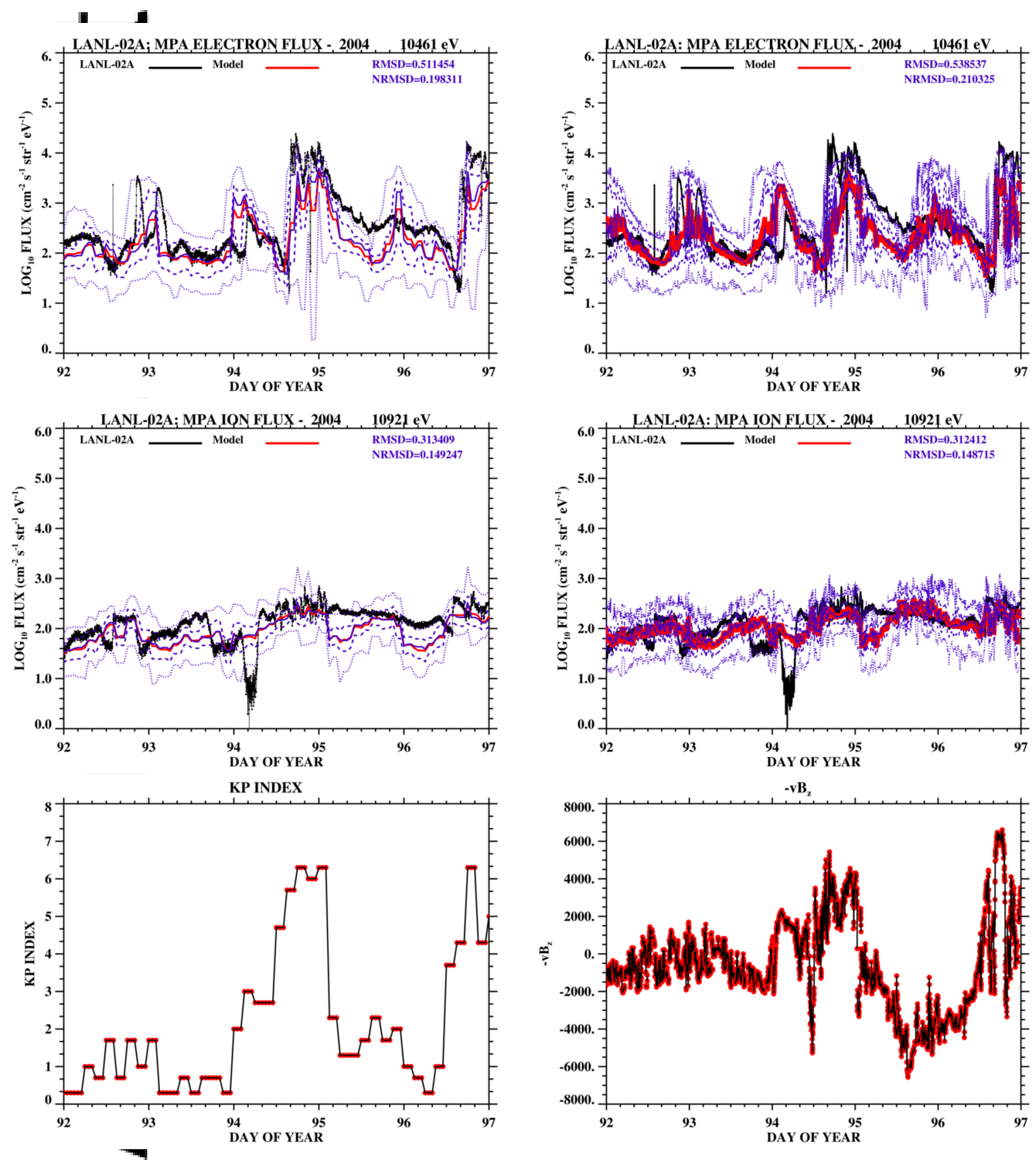

2016sw001409-f06-z-.eps 

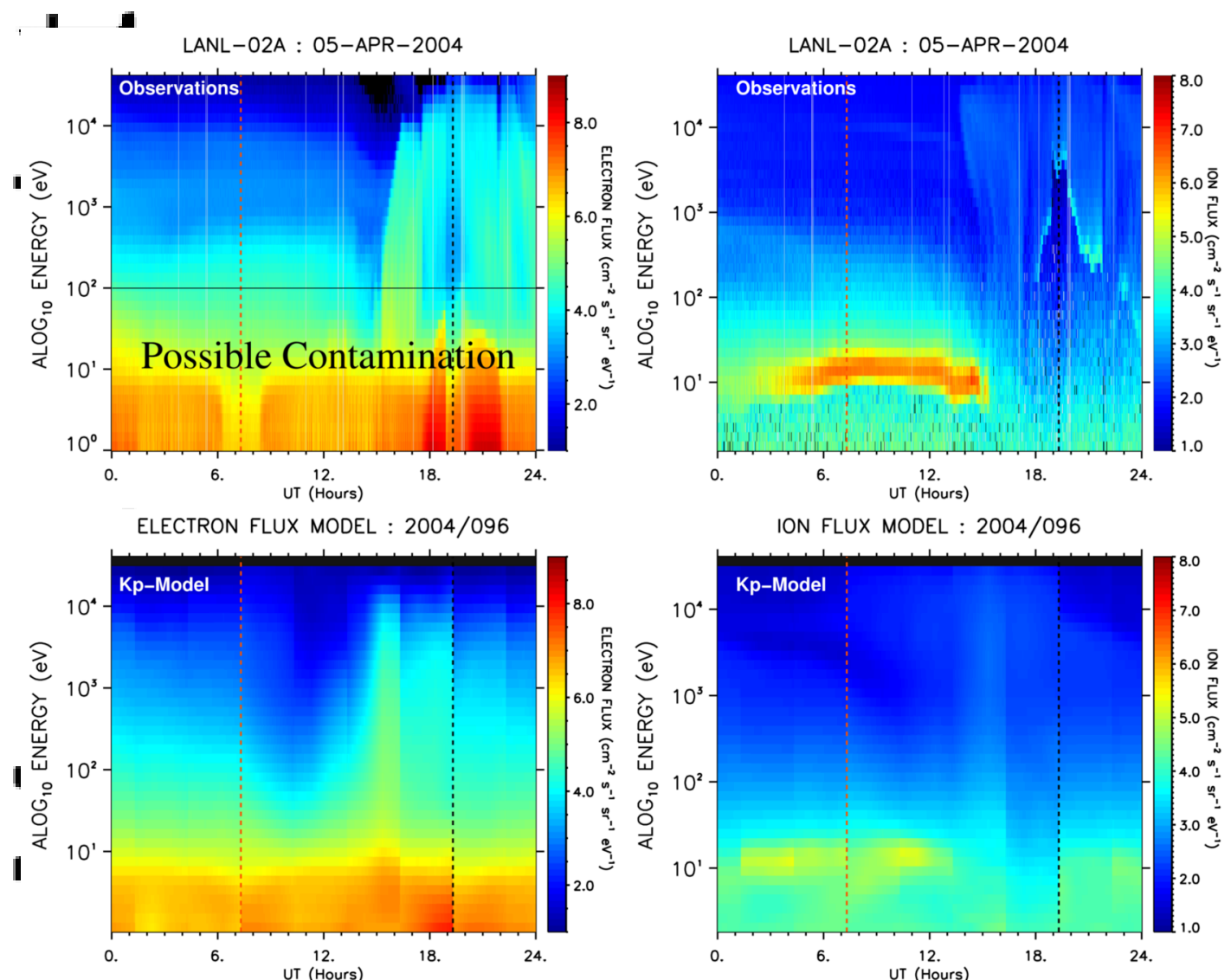

ION FLUX MODEL : 2004/096

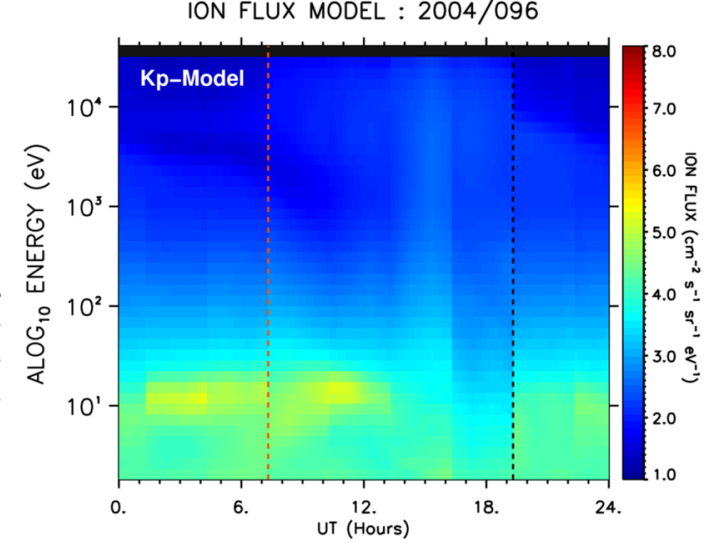

ELECTRON FLUX MODEL : 2004/096

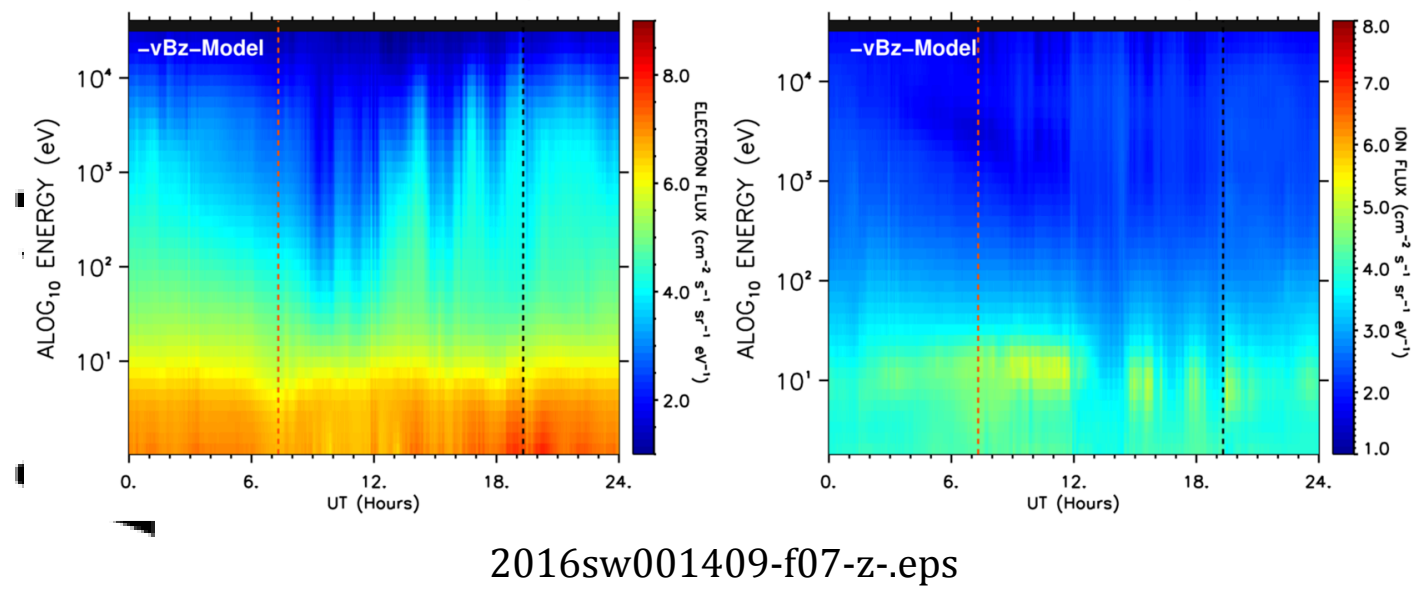

This article is protected by copyright. All rights reserved. 

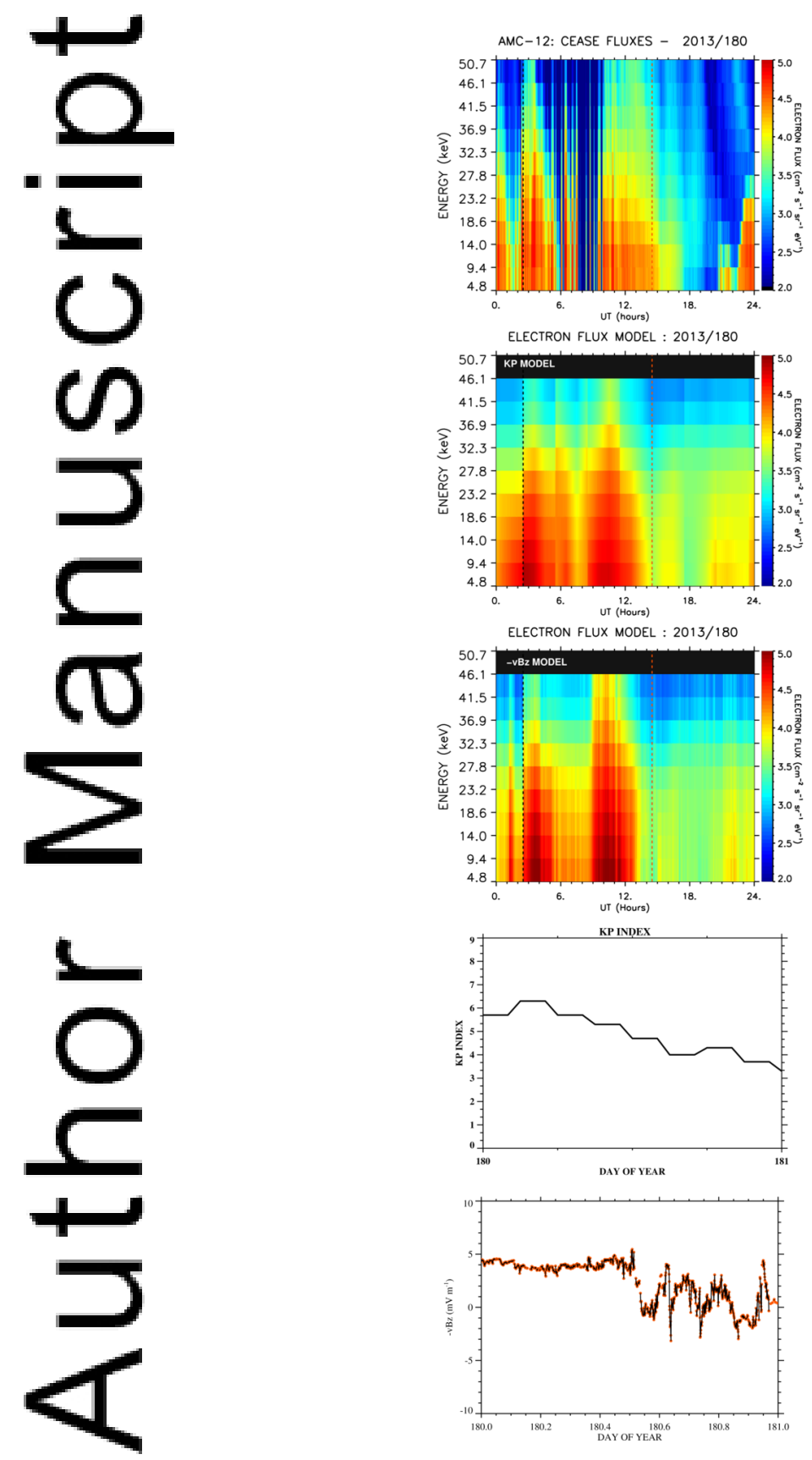

2016sw001409-f08-z-.eps

This article is protected by copyright. All rights reserved. 


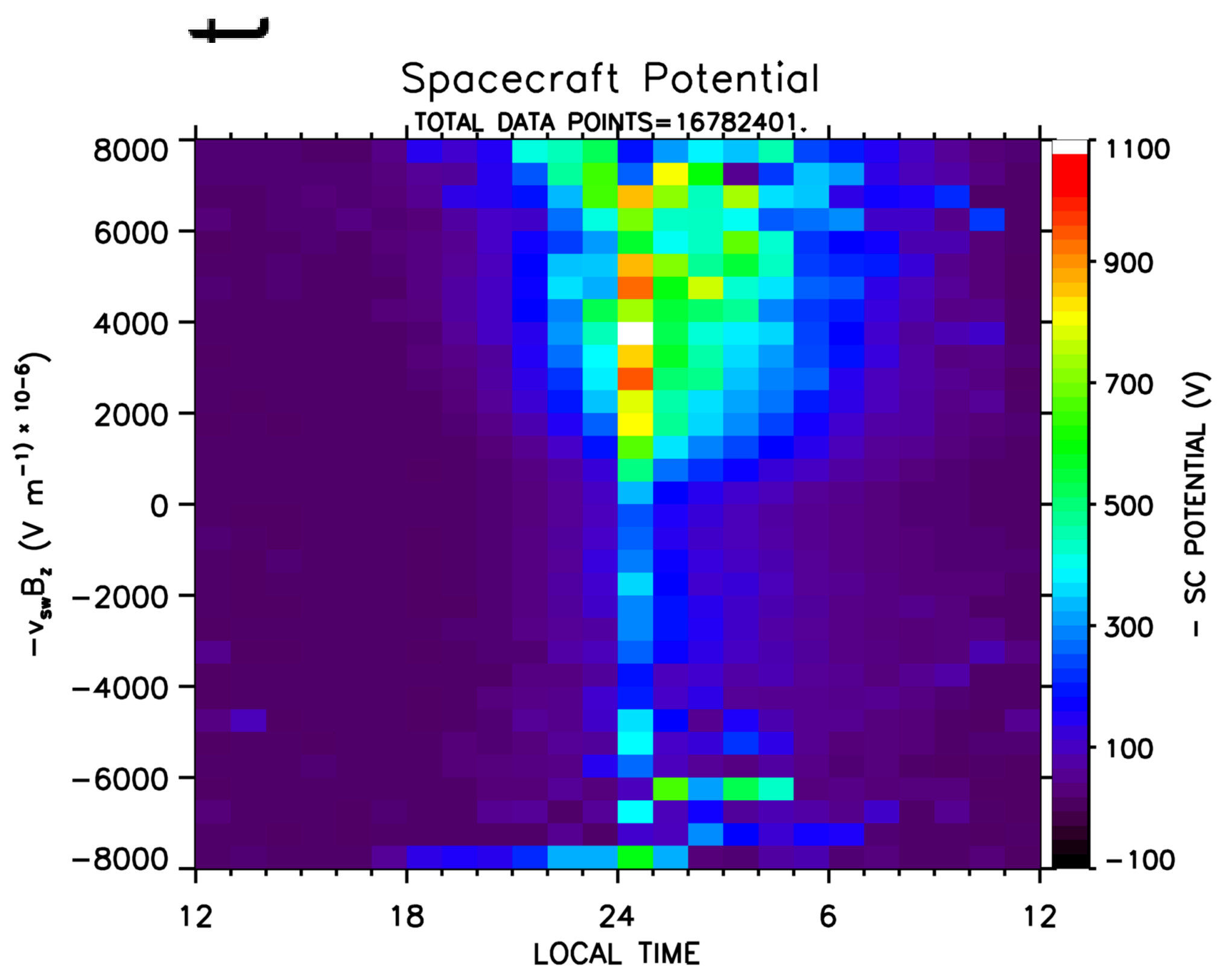

2016sw001409-f09-z-.eps 